\title{
DE DIREGTORES Y ORQUESTAS: ANÁLISIS COMPARADO DE LA POSICIÓN INSTITUCIONAL DEL CONSEJO DE LA JUDICATURA FEDERAL EN MÉXICO*
}

\author{
DIRECTORS AND ORCHESTRAS: A COMPARATIVE ANALYSIS \\ OF THE INSTITUTIONAL POSITION OF THE FEDERAL \\ JUDICIAL COUNCIL IN MEXICO
}

\section{Mauro Arturo RIVERA LEÓN**}

RESUMEN: En el presente artículo se analiza la posición institucional del Consejo de la Judicatura Federal en México. Se argumenta que su posición actual tiene una clara dependencia de la Suprema Corte y que carece de medios que garanticen su autonomía e independencia. Para tales efectos, se estudia en una perspectiva comparada ciertas medidas tendentes a fortalecer su autonomía institucional, como el fortalecimiento de su posición constitucional, la elección de sus miembros, la designación de su presidente y el régimen de impugnación de sus decisiones. Se argumenta que el régimen adoptado por la reciente reforma constitucional de 2021 atiende las problemáticas sólo parcialmente ya que, por un lado, dejó importantes problemas sin resolver y, por el otro, inclusive, genera nuevas incógnitas.

Palabras clave: Consejo de la Judicatura Federal, autonomía constitucional, integración orgánica.
ABSTRACT: This article analyses the institutional position of the Federal Judicial Council in Mexico from a Comparative Law approach. It argues that the Federal Judicial Council's configuration is subordinated to the Mexican Supreme Court and lacks institutional autonomy. This study analyses several options in comparative law that may ensure the institutional autonomy of the Council, such as the strengthening of its constitutional position, the election of the council's president, and the regime pertaining to the overrule of its decisions. The article argues that the recent 2021 constitutional amendment did not provide a solution to a variety of concerns and may have even created further complications.

Keyzords: FederalJudicial Council, constitutional autonomy, members of the council.

* Recibido el 17 de noviembre de 2020; aprobado el 2 de febrero de 2021.

** ORCID: 0000-0003-4964-7086. Doctor en Derecho por la Universidad Complutense de Madrid; profesor de la Universidad Iberoamericana; investigador nacional nivel I (SNI).Twitter@MauroArturo. Correo electrónico: arturo.riverale@gmail.com. Agradezco a

Boletín Mexicano de Derecho Comparado, nueva serie, año LIII, núm. 159, septiembre-diciembre de 2020, pp. 1139-1179.

Esta obra está bajo una Licencia Creative Commons Atribución-NoComercial-SinDerivar 4.0 Internacional, IIJ-UNAM. 
Esta revista forma parte del acervo de la Biblioteca Jurídica Virtual del Instituto de Investigaciones Jurídicas de la UNAM

SUMARIO: I. El Consejo de la fudicatura Federal: consideraciones introductorias. II. En defensa de la autonomía. III. Conclusiones. IV. Bibliografia.

\section{El Consejo de la Judicatura Federal mexicano: CONSIDERACIONES INTRODUCTORIAS}

El Consejo de la Judicatura Federal en México (CJF o Consejo) es un órgano creado en virtud de la reforma constitucional de 31 de diciembre de 1994 (doctrinariamente presente en el debate desde la propuesta de Fix-Zamudio 1967, 119-121). Esta reforma pretendió perfilar a la Suprema Corte como Tribunal Constitucional al dotarla de mecanismos propios del control concentrado y reducir sus facultades de legalidad. La determinación mexicana de decantarse por un Consejo de la Judicatura sigue la línea sentada por países como España en su Consejo General del Poder Judicial, Italia en su Consiglio Superiore della Magistratura (Sotelo 2017, 77), Francia en su Conseil Supérieur de la Magistrature o Polonia en el Krajowa Rada Sadownictwa, que privaron a los ministerios de justicia de su tradicionalmente asumida función de gobierno y administración (López Aguilar 2017, 684). ${ }^{1}$

Sin embargo, en el caso mexicano, el Consejo de la Judicatura no pretendía disminuir la influencia del Poder Ejecutivo por medio de un Ministerio de Justicia. Desde 1917, el modelo de administración había sido judicial basado en la Suprema Corte. La creación de un Consejo de la Judicatura fue una medida conceptualizada como una forma de evitar la distracción de la Suprema Corte en las labores administrativas que había desempeñado en la judicatura tradicionalmente bajo la Constitución de Querétaro. Por tanto, la creación del CJF, en el caso mexicano, vino a reemplazar las funciones de la antigua Comisión de Gobierno y Administración, dependiente de la Suprema Corte.

En el caso de la reforma constitucional de 1994, buena parte de la atención académica se centró en la nueva regulación dada a las controver-

\footnotetext{
Rodrigo Galán sus generosos comentarios en este artículo. Los posibles errores son, naturalmente, de mi exclusiva responsabilidad.

1 En opinión de Pizzoruso $(1981,414)$ "l'attribuzione al Consiglio superiore della maggior parte delle funzioni amministrative inerenti all'esercizio della giurisdizione si presenta come un fondamentale strumento di tutela dell'indipendenza «esterna» dei giudici e della magistratura complessivamente considerata".
} 
Esta revista forma parte del acervo de la Biblioteca Jurídica Virtual del Instituto de Investigaciones Jurídicas de la UNAM

sias constitucionales, así como la creación de una acción de inconstitucionalidad y no tanto en la introducción de este órgano cuya finalidad es la de gobierno, administración y disciplina del Poder Judicial.

Para Carpizo, lo que persigue la creación de este tipo de órganos es garantizar la carrera judicial, así como incentivar la promoción y designación de jueces mediante un sistema objetivo de méritos que incida, consecuentemente, en su independencia (Carpizo 2000, 212). Los consejos pueden tener influencia favorable al permitirle a la judicatura dedicarse en su totalidad a las funciones jurisdiccionales, hacer eficientes y objetivar las decisiones de sanción y nombramientos, garantizar la independencia de los jueces, eliminar el clientelismo o corporativismo judicial o coadyuvar a exigir responsabilidades a los propios jueces. Con frecuencia se ha denominado a los consejos como un "gobierno" o "autogobierno" judicial, aunque este último término ha sido bastante discutido (Giacobbe 1994, 95).

Las funciones del CJF mexicano se encuentran desarrolladas en el artículo 100 constitucional. Tiene facultades de capacitación (Báez Silva 2003, 345-353), promoción, designación, adscripción y vigilancia de los miembros del Poder Judicial de la Federación exceptuando a la Suprema Corte y al Tribunal Electoral del Poder Judicial de la Federación. Institucionalmente, se encuentra incardinado dentro del propio Poder Judicial y tiene independencia técnica y de gestión para emitir sus resoluciones. La integración del CJF es mixta, pues de los siete consejeros, cuatro son miembros del Poder Judicial, dos son designados por el Senado y uno por el presidente de la República.

La caracterización del CJF mexicano tiene ciertos rasgos definitorios. En primer lugar, tiene funciones meramente administrativas y no ejerce facultades jurisdiccionales, a excepción de la resolución de los conflictos entre el Poder Judicial de la Federación y sus trabajadores y la solución de procedimientos disciplinarios que tienen cariz constitucional a juicio de Gutiérrez (2018, 285), facultad que explícitamente y sólo como excepción, le asigna el artículo 123.B.12 de la Constitución. ${ }^{2} \mathrm{Al}$ igual que otros

2 La resolución de conflictos laborales del Poder Judicial no es la función principal del CJF y bien podría prescindirse de la misma. Recordemos que, en el caso mexicano, un particular entendimiento de la "autonomía" de diversos órganos ha llevado a reformar la Constitución para que éstos resuelvan sus propios conflictos laborales, privando a sus trabajadores de una jurisdicción ordinaria (este es el caso del Tribunal Electoral del Po- 
Esta revista forma parte del acervo de la Biblioteca Jurídica Virtual del Instituto de Investigaciones Jurídicas de la UNAM

consejos, no ostenta una representación de los jueces ni del Poder Judicial. ${ }^{3}$ Sin embargo, a diferencia del Consejo General del Poder Judicial español, sobre el cual hubo un intenso debate (Gerpe 1992, 182) y el Consiglio Superiore della Magistratura italiano (Massimo 2020, 11), el CJF mexicano no tiene una posición constitucional autónoma, sino que se integra estructuralmente dentro del Poder Judicial y no como un actor al margen de la tríada de poderes. En el caso mexicano, como veremos, su configuración lo hace dependiente de la Suprema Corte.

Este trabajo está organizado de la siguiente manera. En la sección I se ofrecen consideraciones introductorias al nacimiento del CJF remarcando que, paradójicamente, el caso mexicano disiente de sus homólogos europeos en tanto que su introducción no pretendió privar al Ministerio de Justicia de atribuciones respecto a la judicatura, sino delinear a la Suprema Corte con un perfil más idóneo para desempeñar las funciones de Tribunal Constitucional material y eliminar el corporativismo. En la sección II se analiza la posición constitucional del CJF y, correlativamente, la inexistencia de vías defensivas de su competencia, se estudia su integración (método de elección, origen, número y duración de sus integrantes), así como la Presidencia de derecho del CJF por parte del presidente de la Suprema Corte. De igual forma, se analiza el régimen de impugnación de las determinaciones del CJF, y la facultad, recientemente introducida por reforma constitucional de 2021, de concentrar en órganos jurisdiccionales específicos casos concretos exceptuando turno y competencia. En la sección III se ofrecen las conclusiones.

La presente investigación parte de la hipótesis de que el CJF tiene una posición dubitativa que lo hace dependiente de la Suprema Corte. Para ello, sostiene que debería concedérsele una posición constitucional autónoma (y no incardinada en el Poder Judicial) con el consecuente acceso

der Judicial de la Federación, Suprema Corte y CJF, inter alia). Los trabajadores de estos órganos, en el caso mexicano, se ven forzados a litigar ante ellos mismos sus problemas laborales y no frente a una jurisdicción laboral neutral al conflicto. Este aspecto, altamente cuestionable, no será abordado en este artículo por ser ajeno a su materia principal.

3 Ha existido un debate sobre si los consejos de la judicatura son representativos per se del Poder Judicial o sus jueces. En el caso español, esta pretensión fue rechazada por el Tribunal Constitucional. En concreto, se adujo que "al configurarse constitucionalmente como su «órgano de gobierno», no podría ser, ni siquiera a efectos procesales, «representante» del Poder Judicial, pues ello estaría en contradicción con el principio constitucional de independencia de Jueces y Magistrados". STC 45/1986, del 17 de abril, FJ 5. 
Esta revista forma parte del acervo de la Biblioteca Jurídica Virtual del Instituto de Investigaciones Jurídicas de la UNAM

a mecanismos defensivos de su competencia, permitirle la elección de su presidente, incrementar su composición e introducir elementos de elección interna judicial en algunos de sus consejeros, así como una reforma al sistema de revisión de sus determinaciones por parte de la Suprema Corte. A pesar de que algunos de estos aspectos fueron abordados parcialmente en la reciente reforma constitucional de $2021,{ }^{4}$ dicha reforma no solucionó la totalidad de problemáticas y, de hecho, creó algunas nuevas.

\section{EN DEFENSA DE LA AUTONOMÍA}

La motivación principal para la creación del GJF fue la delegación de funciones administrativas de la Suprema Corte para permitirle a ésta ejercer más efectivamente un rol material de Tribunal Constitucional. Esta visión escindía a la Suprema Corte del resto del Poder Judicial federal. Aparejado a la concentración de facultades de constitucionalidad también se visualizaba como objetivo la disminución de influencia y clientelismo por parte de la Suprema Corte. No sólo la Corte debía alejarse de la administración de la judicatura, sino también la judicatura evitar la influencia de la Corte, que se pensaba especialmente innecesaria bajo la nueva noción de ésta.

¿Tiene el CJF la autonomía e independencia suficientes para el desarrollo adecuado de sus funciones? ¿Cumple la presidencia nata del CJF un rol adecuado con la reducción de las funciones de legalidad de la Suprema Corte? ¿Es idónea su integración? ¿Garantiza la independencia externa e interna de la judicatura?

4 Advertencia metodológica: en el curso del proceso de arbitraje ciego por pares de este artículo se aprobó en ambas cámaras la reforma constitucional sobre el Poder Judicial de 2020-2021 (propuesta por el ministro presidente de la Suprema Corte y que Presidencia de la República hizo suya). Al momento de la última revisión de este artículo (28/01/2021) se han emitido 6 votos aprobatorios por las legislaturas de las entidades federativas. Dada la dinámica de reforma constitucional en México, se ha consolidado un uso político de aprobación rutinaria de las reformas por parte de las entidades federativas. Por ello, este estudio presupone (suposición nada arriesgada) que ha sido aprobada dicha reforma constitucional al momento de la publicación editorial de este artículo y analiza el texto constitucional incluyendo dichas reformas. El texto de la reforma aprobada y turnada a las entidades federativas está disponible en el sitio oficial de la Cámara de Diputados: https://bit.ly/362yDOL (última consulta 26/01/2021), aunque el autor estima que al momento de la publicación definitiva del artículo será texto constitucional vigente. 
Esta revista forma parte del acervo de la Biblioteca Jurídica Virtual del Instituto de Investigaciones Jurídicas de la UNAM

\section{Posición constitucional}

El CJF carece de la autonomía constitucionalmente garantizada a muchos de sus homólogos y se incardina directamente dentro del Poder Judicial. No tiene, por tanto, la categoría de "órgano constitucional autónomo" conceptualmente empleada en México para aludir a órganos fuera de la tríada, no subordinados a los tres poderes "clásicos", que Dussauge $(2016,478)$ ha referido como constitucionalización de instituciones no mayoritarias.

En el derecho comparado son abundantes los ejemplos contrarios. El Consejo General del Poder Judicial español (artículo 122.3 de la Constitución Española) tiene la categoría de órgano constitucional (Aguiar de Duque 2008, 1890) y, a pesar de la fuerte discusión (García Roca 1987, 70; Gerpe 1992, 182 y Terol Becerra 1990, 141-154), es pacífico que no forma parte del Poder Judicial (Fernández Riveira 2016, 381), a pesar de que Valls incorrectamente así lo haya afirmado (citado por Rebollar y Rosales 2016, 216). Algo similar acontece con el Consiglio Superiore della Magistratura establecido en el artículo 104 de la Constitución italiana, que es conceptualizado como un órgano de relevancia constitucional (Luciani 2020, 11). Fuera del debate sobre si puede atribuírsele la categoría de "órgano constitucional", es pacífico que su autonomía constitucional está garantizada y carece de incardinación en la tríada de poderes (Silvestri 2017, 21). La misma situación es predicable del Krajowa Rada Sadownictwa (Consejo Nacional de la Judicatura polaco) establecido en el artículo 187 de la Constitución polaca que es un órgano constitucional central del Estado (Sobczak 2010, 816).

En el caso mexicano, al describir al CJF, algunos autores han empleado la expresión de órgano "semi-autónomo" (Ackerman 2009, 38 y, siguiendo esta terminología, Hernández y Chávez 2019, 124). Empero, la ausencia de autonomía es clara. Existe una estructura jerárquica respecto del Poder Judicial y el CJF tiene un diseño institucional subordinado a la Suprema Corte. Garoupa y Ginsburg $(2009,122)$, en su estudio comparativo, calificaron al CJF mexicano como un "Strong hierarchical Council" a diferencia de Italia o Francia en que sostenían que el respectivo Consejo resultaba "strong non-hierarchical".

Por tanto, a pesar de que tenga un amplio aparato burocrático, el CJF no deja de ser un órgano de funcionamiento administrativo interno de un 
Esta revista forma parte del acervo de la Biblioteca Jurídica Virtual del Instituto de Investigaciones Jurídicas de la UNAM

poder estatal. Carpizo (2000) calificó la posición del CJF como de abierta subordinación, opinión compartida por relevantes organizaciones internacionales (Alto Comisionado de las Naciones Unidas para los Derechos Humanos en México 2003, 13), mientras que Gutiérrez (2018, 179) emplea la velada terminología de "preeminencia".

Algunas voces en la doctrina jurídica mexicana (Cárdenas Gracia 1996, 27 1) se han alzado propugnando la consagración del CJF como un órgano constitucional autónomo para garantizar su autonomía y total independencia. La actual posición que tiene con respecto al Poder Judicial produce algunos problemas que deben ser discutidos.

Por un lado, al no tener una autonomía garantizada constitucionalmente, carece de paridad en su relación con los poderes, lo que se refleja en la subordinación patente frente a la Suprema Corte. Recordemos que el contexto mexicano no creó un CJF como forma de reducir la injerencia del Ejecutivo (como en el caso español o italiano), sino como forma de reducir la injerencia de la propia Suprema Corte, en primer punto, y como una reacción a su concepción de Tribunal Constitucional material.

Una de las consecuencias de la posición institucional subordinada del CJF es que tiene vedado el acceso a recursos jurisdiccionales para defender su autonomía por ejemplo, la hipótesis de una controversia constitucional sub specie legis). Por tanto, jurídicamente se encuentra en riesgo de intromisiones de poderes externos, incluido, naturalmente, del propio Poder Judicial a quien disciplina y administra. La vía idónea para la defensa de las atribuciones constitucionales del CJF en México sería la controversia constitucional. El listado original de la legitimación en la controversia constitucional mexicana era limitado, lo que había provocado no pocas problemáticas en torno a ciertos órganos constitucionales autónomos. Como respuesta a ello, en junio de 2013 se reformó la Constitución mexicana para conceder legitimación a los órganos constitucionales autónomos en la controversia constitucional. Para ello, se adicionó una fracción al artículo 105.I constitucional después de diversos desencuentros jurisprudenciales. ${ }^{5}$ Esta ampliación había sido sugerida por la doctrina

5 La Suprema Corte de Justicia, a partir de 2006, había rechazado sucesivamente la legitimación activa en controversia constitucional de la Comisión Nacional de Derechos Humanos, el Instituto Federal Electoral y el Instituto Federal de Acceso a la Información Pública y Protección de Datos. En el orden anteriormente enumerado, véase los recursos de reclamación 20/2007-PL; 58/2007-PL y 46/2010 CA. Tal cerrazón resultaba curiosa 
Esta revista forma parte del acervo de la Biblioteca Jurídica Virtual del Instituto de Investigaciones Jurídicas de la UNAM

(Salazar y Salgado 2009, 591; Ovalle Favela 2011 y Herrera García 2005, 290). Empero, el CJF, al carecer de la categoría de órgano constitucional autónomo o de otra mención expresa de legitimación, no puede presentar tales mecanismos de defensa.

El problema no es de simple configuración normativa. Si en este momento se reformase la lista del artículo 105 constitucional para darle legitimación al CJF tendríamos la paradoja de que el Poder Judicial (Suprema Corte) recibiría una solicitud del propio Poder Judicial (en el que se integra el CJF) de tutela competencial. Más aún, tomando en cuenta que el presidente de la Suprema Corte de Justicia es presidente nato del CJF, tendríamos un potencial motivo para que uno de los miembros se abstenga de conocer de la controversia constitucional.

Por ello, consideramos que debería someterse a discusión la conveniencia de configurarlo como órgano constitucional autónomo como ha propuesto también Nieto $(2011$, 265), en atención a las funciones de vital trascendencia que ostenta el CJF, así como a la independencia que ha pretendido otorgársele. No es posible considerarlo sujeto legitimado para acudir a las controversias constitucionales sin previamente garantizarle una posición constitucional autónoma ajena a la Suprema Corte que resuelve dicho medio de control.

Una reforma de esta naturaleza tendría como correlato natural la legitimación del CJF para plantear controversias constitucionales y defender, de esta manera, sus atribuciones en su calidad de órgano constitucional autónomo, como ocurre en el caso italiano, español o francés (Carpentier 2006, 89-91).

Soluciones análogas a la descrita parecen haber sido adoptadas también por España, Italia y, matizadamente, Polonia, en tanto han previsto, por vías diferentes, la defensa de las atribuciones constitucionales de sus respectivos consejos. En España, la Ley Orgánica del Tribunal Constitucional (artículo 59.3) expresamente lo habilita como sujeto legitimado para acudir al conflicto entre órganos constitucionales como ha debatido la doctrina (García Roca 1987, 70 y Gómez Montoro 1992, 341). De he-

en tanto, en el 2006 (CC 31/2006) se había sostenido que el clausulado del 105 constitucional era sólo enumerativo. La doctrina afirmó que la ausencia de vía defensiva los colocaba en una "situación de indefensión frente a los actos de otros órganos o poderes del Estado que pudieran invadir su esfera competencial” (Vázquez Mata 2010, 357). 
Esta revista forma parte del acervo de la Biblioteca Jurídica Virtual del Instituto de Investigaciones Jurídicas de la UNAM

cho, a su instancia, ha sido resuelto uno de los pocos conflictos planteados hasta la fecha (STC 45/1986) en el que éste impugnaba una reforma al método electivo de los vocales al sostener que minaba la autonomía del propio Consejo (Trujillo 1995, 126).

El caso italiano es distinto, pues la vía procesal en Italia (conflitto tra poteri dello Stato) carece de una enumeración tasada y cerrada de sujetos procesales (Zagrebelsky 1977, 382) como sí tiene la controversia constitucional en México o el conflicto entre órganos constitucionales en España. El debate se ha presentado en torno a si el Consiglio della Magistratura puede o no expresar definitivamente la voluntad de un poder del Estado, debate resuelto en un sentido positivo por la Corte Constitucional. De hecho, en 1992 se dio un fuerte conflicto de atribuciones entre el Consejo de la Magistratura (CSM) y el Ministro de Justicia (Sentencia 379/1992) en que se terminó afirmando rotundamente la legitimación del primero (Sicardi 1993, 126).

El caso polaco es sumamente atípico. El artículo 189 constitucional, que configura la legitimación para acudir al conflicto entre órganos, evita toda referencia al Consejo. Sin embargo, este aparente "olvido" podría haberse entendido corregido por la mención que el artículo 192 constitucional hace respecto a la posibilidad de que el Consejo acuda al Tribunal Constitucional para la defensa de la independencia de jueces y tribunales, lo que ha generado un debate sobre si no existe una representación distante procesal de los jueces por el Consejo (Garlicki 2012, 348). Sin embargo, en el 2008 se presentó la inusitada situación del rechazo por parte del presidente del nombramiento de un juez propuesto por el Consejo lo que derivó en la interposición de un conflicto entre órganos constitucionales. La sentencia 97/5/A/2008 (Kpt 1/08) rechazó la legitimación activa del Consejo (ausencia criticada por Sarnecki 2009, 12) por no haber sido incluido en el listado del artículo 192 constitucional (Sułkowski 2008, 4766). La situación podía atemperarse en Polonia dado que el Consejo de la Judicatura cuenta con legitimación para promover acciones de inconstitucionalidad (wniosek). Por ello, al menos puede promover conflictos sub specie legis. En Polonia la solución del conflicto estribó en concebir un mecanismo indirecto entre los sujetos legitimados activamente y el resto de los órganos constitucionales que no tienen legitimación activa. Es posible que un órgano con legitimación plantee un conflicto entre dos órganos constitucionales centrales del Estado que carecen, a su vez, de tal legitimación. 
Esta revista forma parte del acervo de la Biblioteca Jurídica Virtual del Instituto de Investigaciones Jurídicas de la UNAM

La legitimación en Polonia no implica el interés de la parte (una especie de modelo de defensor objetivo del esquema de distribución competencial en la Constitución). Para el caso de un eventual conflicto por actos, el Consejo polaco tendría que acudir primero a la Suprema Corte y que ésta, a su vez, plantease el conflicto, como efectivamente aconteció en la sentencia reseñada. ${ }^{6}$

Aunado a lo anterior, la propia Comisión de Venecia $(2007,10)$ ha sostenido que una forma apropiada de garantizar la independencia judicial es establecer consejos de la judicatura con "garantías constitucionales en su composición, poderes y autonomía”. Las garantías deben entenderse tanto de forma institucional como procesal.

De las pinceladas de derecho comparado que hemos estudiado con anterioridad, parece advertirse que la posición no subordinada del Consejo es una garantía de su independencia y, consecuentemente, le permite (con algunos matices en el caso polaco) la defensa de sus atribuciones por la vía de los diferentes modelos de resolución de controversias constitucionales. A efectos de mejorar el funcionamiento e independencia del CJF mexicano, debe garantizársele una posición constitucional de autonomía con el correlativo acceso a medios procesales para su defensa.

\section{Los retos de la integración}

Uno de los elementos más significativos en el funcionamiento de las instituciones es su integración. La integración, como faceta de estudio orgánica, toma en cuenta diversos elementos, a saber, la integración numérica, el origen de los miembros, así como el método de elección para ello. Por integración numérica debe entenderse el número de miembros que componen al Consejo. El origen de los miembros alude a la existencia de estratos profesionales respecto del cual debe integrarse el órgano (jueces, abogados postulantes, fiscales). Finalmente, la integración desde la perspectiva electiva analiza cuáles órganos o sujetos políticos serán encargados de nominar a los integrantes del Consejo. Dada la estrecha relación de las últimas dos facetas, en este estudio analizaremos primero la integración desde una perspectiva numérica y, finalmente, de forma correla-

6 Esta vía indirecta se encontró perfilada en el artículo 44 de la Ustawa o Krajowej Radzie Sąownictwa y fue planteada como parte de las reformas de 2008.

Esta obra está bajo una Licencia Creative Commons

Atribución-NoComercial-SinDerivar 4.0 Internacional, IIJ-UNAM.

Boletin Mexicano de Derecho Comparado, núm. 159, septiembre-diciembre de 2020, pp. 1139-1179. 
Esta revista forma parte del acervo de la Biblioteca Jurídica Virtual del Instituto de Investigaciones Jurídicas de la UNAM

cionada estudiaremos el origen o estrato de los integrantes y los órganos proponentes respectivos.

Integración numérica. El CJF mexicano, a diferencia de sus homólogos europeos, se caracteriza por una integración reducida. Lo integran el presidente de la Corte (que preside de forma nata el Consejo), tres consejeros elegidos por el Pleno de la Suprema Corte de entre magistrados de circuito y jueces de distrito, dos consejeros elegidos por el Senado y uno elegido por el Ejecutivo. Los 7 miembros del CJF, ciertamente, puede dar la impresión de un Consejo reducido si lo contrastamos con los 25 miembros del Consejo Nacional de la Judicatura polaco, los 27 miembros del Consiglio Superiore della Magistratura italiano ${ }^{7}$ o los 21 miembros del Consejo General del Poder Judicial español (20 vocales y un presidente nato).

Los números reducidos pueden ser un problema para que el Consejo efectivamente cumpla todas sus tareas. A ello debe añadirse que el presidente nato tiene una carga de trabajo excesiva al administrar y representar a la Suprema Corte y participar semanalmente en sus tres sesiones de Pleno (con el consecuente estudio de los asuntos). La Presidencia del CJF es nominal, pues no existe un régimen de dedicación absoluta. La ley, además, exige de 3 consejeros para integrar cada Comisión prevista en la Ley Orgánica del Poder Judicial de la Federación (LOPJF). Por tanto, parecería sensato elevar el número de consejeros a efectos de darles una mayor capacidad de trabajo en comisiones. Piénsese que sólo el artículo 77 de la LOPJF exige, cuando menos, la existencia de las comisiones de administración, carrera judicial, disciplina, creación de nuevos órganos y la de adscripción.

De tal suerte, en virtud de las funciones del CJF, consagradas en la LOPJF, actualmente es necesario, cuando menos, la existencia de 15 consejeros a efectos de que cada uno integre sólo una comisión. Bajo el modelo actual, todos los consejeros deben integrar cuando menos dos comisiones y alguno una tercera, lo cual incluye a su presidente (al mismo tiempo presidente de la Suprema Corte). Un número tentativo, sujeto a discusión, podría ser el de 16 consejeros, a efectos de que se integren las comisiones respectivas y el presidente cumpla sólo funciones administrati-

7 La Composición en Italia no se encuentra definida totalmente en la Constitución. Debe acudirse también a la Ley 195 del 24 de marzo de 1958, modificada sucesivamente por la Ley 695/1975 y posteriormente la 44/2002.

Esta obra está bajo una Licencia Creative Commons 
Esta revista forma parte del acervo de la Biblioteca Jurídica Virtual del Instituto de Investigaciones Jurídicas de la UNAM

vas del propio Consejo. Poco a poco, parece que la doctrina mexicana ha comenzado a inclinarse hacia la noción de la necesidad de un incremento del número de miembros del CJF (Fix-Fierro 2018, 35 y Gómez Marinero 2008, 2020).

El incremento de miembros del CJF ciertamente podría generar un órgano menos compacto que el actual. Sin embargo, ello implicaría privilegiar la labor especializada de las comisiones frente al Pleno. Por ejemplo, Voermans y Pim $(2003,110)$ observan que la práctica europea recomienda consejos numéricamente amplios, de 15 miembros o más y sugieren mantener sistemas electivos que combinen tanto requisitos de pertenecía a estratos concretos como difuminar las autoridades que intervienen en los nombramientos. Resulta indicativo también que en el debate italiano, español o polaco, de los muchos aspectos fuertemente discutidos, la amplitud numérica no ha sido uno de ellos, por lo que la práctica demuestra que es posible dotar de funcionalidad a estas conformaciones.

Origen y elección de los integrantes. El origen por estrato y los órganos proponentes son facetas que, si bien son estrictamente distintas, tienen una correlación natural. Es común que cuando la nominación recae en ciertos actores políticos los perfiles de los elegidos tendrán también, en consecuencia, una orientación particular.

En cuanto a la primera faceta (origen por estrato profesional), la doctrina parece haber sido unánime en señalar que es conveniente mantener una mayoría de miembros de origen judicial en el CJF, preferentemente de la categoría de juzgadores.

El CJF mexicano cumple en la actualidad con el estándar. A los tres consejeros de origen judicial electos por la Suprema Corte (entre jueces y magistrados), debe sumarse el propio ministro presidente de la Corte que, naturalmente, proviene de la propia judicatura al menos estructuralmente (porque, en turno, no es obligatorio que provenga de la carrera judicial como ocurre actualmente). Ello nos da 4 sobre 7 consejeros de origen judicial.

En el caso mexicano, el origen judicial de los miembros se encuentra predeterminado por la Constitución, al menos en los electos por la Suprema Corte, pero no constituye un tope. ¿Qué implica esto? Que las designaciones realizadas por Presidencia o el Senado pueden también comprender miembros del Poder Judicial, aunque allí no es necesario que lo hagan. 
Esta revista forma parte del acervo de la Biblioteca Jurídica Virtual del Instituto de Investigaciones Jurídicas de la UNAM

Actualmente, los miembros de origen judicial prefijados en el CJF representan $57 \%$ de la totalidad del órgano, un porcentaje muy similar al $60 \%$ polaco, $62 \%$ italiano y $57 \%$ español. La preponderancia de consejeros de origen judicial debe mantenerse si se aumentan los miembros del Consejo para preservar la independencia de sus resoluciones y del Poder Judicial administrado.

La propia Suprema Corte mexicana ha interpretado, inter alia en la CG 32/2017, AI 15/2017, CG 81/2017 y CG 112/2018 que, para garantizar la autonomía del Poder Judicial, los consejos de las judicaturas locales deben conformarse por una mayoría de integrantes provenientes de la judicatura (aunque no ha delineado un mecanismo electivo específico y su interpretación ha sido notablemente empañada por intentar replicar la integración del CJF delineado constitucionalmente).

Ahora bien, el hecho de que sea positivo tener una mayoría proveniente de la judicatura no conduce indefectiblemente a concluir que el nombramiento debe ser realizado necesariamente por la Suprema Corte. En Italia ${ }^{8}$ existe una importante participación de los jueces en la elección de los miembros del Consejo y lo mismo llegó a ocurrir en la evolución del constitucionalismo español (1980-1985). Éste fue el caso del primer modelo del Consejo General del Poder Judicial español en la Ley Orgánica del Poder Judicial 1/1980 (LOPF), que parecía inferirse de la propia Constitución (Díez-Picazo 2018, 1728 y Rosado Iglesias 2018, 365). Empero, la LOPJ 6/1985 modificó el sistema para establecer una designación parlamentaria de todos los vocales entre una lista de propuestas de candidatos por asociaciones judiciales y jueces y magistrados no asociados. El actual esquema (LOPJ 4/2013), cuya constitucionalidad se confirmó en la STC $191 / 2016$, se forma por un sistema de designación parlamentaria con avales de los miembros de la carrera judicial. Hay quien acusa la actual politización del Consejo General en el caso español al abandono de este sistema de elección interno en favor de un sistema de designación parlamentaria directo o con atenuantes (Torres 2018, 1782).

A diferencia de los ejemplos citados, en México los jueces ni siquiera intervienen en el proceso de designación de consejeros. A pesar de que el

8 El sistema electivo se delinea en la Ley del 24 de marzo de 1958, número 195, de título "Norme sulla costituzione e sul funzionamento del Consiglio superiore della Magistratura". 
Esta revista forma parte del acervo de la Biblioteca Jurídica Virtual del Instituto de Investigaciones Jurídicas de la UNAM

artículo 100 constitucional reserva tres consejeros para jueces de distrito y magistrados de circuito, la propia Corte es la encargada de elegirlos y de escoger a su propio presidente que pasa, automáticamente, a formar parte del CJF y presidirlo. La Suprema Corte (que no es lo mismo que la judicatura), elige a 4 de los 7 consejeros (por la conjunción de los 3 consejeros electos y la presidencia de derecho). Este dominio priva de un contrapeso efectivo a la visión del resto de consejeros (Astudillo 2019, 354) dando a la Corte una indiscutible influencia inusitada.

El procedimiento de selección de los consejeros a manos de la Suprema Corte no estaba contemplado originalmente. En 1994, cuando el Consejo se introdujo en la Constitución, la insaculación era la regla constitucionalmente prefijada para los miembros de origen judicial. Sería la reforma constitucional de 1999 la que eliminaría la insaculación e introduciría la elección por "el Pleno de la Suprema Corte". Se optó por transformar una elección basada en la imparcialidad de los consejeros judiciales (por su naturaleza no electiva) en una elección en que la Suprema Corte juega el papel primordial.

El procedimiento en la Suprema Corte a partir de 1999 ha venido regulándose por sucesivos acuerdos ad hoc respecto de cada elección específica. Sin embargo, ha conservado su tónica usual. El último acuerdo es el AG 15/2019. El procedimiento regulado es sencillo. Son los propios jueces y magistrados quienes se postulan ante la Suprema Corte enviando una serie de documentos acreditativos y una memoria justificativa con su visión del Consejo y un plan de trabajo. Entre los documentos se encuentra información sobre los resultados de las visitas a su órgano jurisdiccional por parte del CJF, así como información estadística sobre el ingreso y egreso de asuntos en su tribunal.

El resto del procedimiento pertenece enteramente a la Suprema Corte quien, tras comparecencias de los candidatos ante el Pleno, designa por mayorías calificadas (8 votos) y procedimiento de desempate. Por tanto, un órgano no administrado por el CJF (la Suprema Corte) y cuyos miembros no necesariamente provienen de carrera judicial, elije a los representantes del Poder Judicial.

En la actualidad, de hecho, una buena parte de ministros carecen de carrera judicial en el Poder Judicial de la Federación. Sólo 4 de los 11 ministros provienen directamente de magistrados de circuito, el máximo escalafón de la judicatura federal (ministros Pérez Dayán, Piña Hernández, 
Esta revista forma parte del acervo de la Biblioteca Jurídica Virtual del Instituto de Investigaciones Jurídicas de la UNAM

Pardo Rebolledo y Aguilar Morales). El resto proviene de cargos judiciales o materialmente judiciales pero que no pertenecen al Poder Judicial de la Federación (Poder Judicial específicamente administrado por el CJF) o de otros rubros. Éste es el caso del ministro presidente Zaldívar (litigante/ académico); ministro González Alcántara (Poder Judicial local); ministro Laynez Potisek (administración pública federal/Tribunal Federal de Justicia Fiscal y Administrativa); ministra Ríos Farjat (administración tributaria), ministra Esquivel Mossa (Tribunal de Justicia Administrativa local); ministro Gutiérrez Ortiz Mena (administración tributaria), y ministro Fernando Franco González Salas (Tribunal Federal Electoral). ${ }^{9}$

Ello implica que, en la actual integración de la Corte, sólo 36\% de ministros provienen de carrera judicial del propio Poder Judicial de la Federación, mientras que el resto no han tenido contacto con ésta. En efecto, nótese que para ser "ministro" de la Suprema Corte no se requiere carrera judicial ni haber sido juez o magistrado, lo que es natural. Al concebirse como un Tribunal Constitucional material el perfil de los ministros de la Corte difiere del perfil de jueces de distrito y magistrados de tribunales unitarios o colegiados. No es por tanto lógico pensar que dotando a la Corte de la capacidad de elección se garantiza una representatividad de la judicatura en el CJF: únicamente se garantiza una representatividad de las visiones de los miembros de la Corte.

Existen voces que han propugnado por la democratización del CJF, sugiriendo un método electivo de los miembros de naturaleza judicial (Cárdenas Gracia 1996, 167 y 27 1). La opción de elección interna de los jueces puede ser considerada. En primer lugar, contribuye a que los administrados tengan participación directa en la integración del órgano administrador. Recordemos que el propio artículo 100 constitucional exenta a la Suprema Corte de toda administración por el CJF, algo que no ocurre en España en donde no sólo lo administra indistintamente, sino que inclusive integra en su totalidad a los magistrados del propio Tribunal Supremo.

En este sentido, un sistema electivo permitiría que fueran los propios magistrados y jueces quienes eligieran sus consejeros. Se fomentaría no

9 Debe recordarse que Franco González Salas fue magistrado del Tribunal Federal Electoral de 1990 a 1996, esto es, antes de la incorporación de este tribunal al Poder Judicial de la Federación (previamente, tenía un estatus mayormente autónomo). Por ende, su experiencia profesional no está vinculada con la carrera judicial. 
Esta revista forma parte del acervo de la Biblioteca Jurídica Virtual del Instituto de Investigaciones Jurídicas de la UNAM

sólo una cultura democrática interna en el Poder Judicial de la Federación, sino potencialmente una mayor aceptación de las resoluciones del Consejo, aumentando su autonomía respecto a la Suprema Corte de Justicia y descargando a ésta aún más de funciones administrativas.

En segundo lugar, el método electivo presenta a los magistrados y jueces la obligación ética de elegir mejor a aquéllos encargados de promoverlos y sancionarlos. El caso español, que modificó una elección interna de vocales por parte de la judicatura a una elección parlamentaria de todos los vocales, ha visto propuestas doctrinarias para volver a la elección delineada primariamente (Gómez Colomer 2019, 233).

Un sistema de elección puede ayudar a fomentar responsabilidad institucional de los jueces, incrementar la confianza hacia su administración de justicia al haber participado en su designación y provee mayor racionalidad a la decisión de quiénes serán consejeros (Serra Cristóbal 2013, 311-316). Como ha notado la doctrina italiana, la elección por parte de la magistratura fomenta el pluralismo cultural y profesional de los sectores judiciales (Zagrebelsky 2019, 92). Nótese que la Comisión de Venecia $(2007,10)$ ha sostenido que, para garantizar la independencia judicial cuando se ha adoptado un modelo de consejos, "debe elegirse a una mayoría sustancial de los miembros del Consejo de la Judicatura por la judicatura misma" aunque debe reconocerse que ha habido voces disidentes a este aparentemente incontrovertible estado del arte (Lucas Murillo de la Cueva 2017, 367).

Sin embargo, un incremento en el número de miembros del Consejo podría permitir ambas opciones. Dada la especial posición que tiene la Suprema Corte en el sistema jurídico mexicano podría combinarse una parte de los consejeros electos por los propios jueces y magistrados con un menor número de consejeros electos por la Suprema Corte.

No debe olvidarse, sin embargo, que la elección potencial por miembros de la judicatura debe también realizarse con cautela. Una configuración descuidada lleva aparejado el riesgo de la corporativización (Cabellos 2020, 35) o, peor aún, la politización de una judicatura mexicana que, en la actualidad, a pesar de no ser aséptica, no tiene los visos de politización que se perciben en el caso español ante las asociaciones judiciales. Parece, sin embargo, que un consenso en la doctrina y la práctica de los estados europeos (Comité de Ministros 2011, 12) es que los beneficios de la elección interna, como la pluralidad de visiones judiciales (Benvenuti 2020, 
Esta revista forma parte del acervo de la Biblioteca Jurídica Virtual del Instituto de Investigaciones Jurídicas de la UNAM

29) superan los riesgos de la politización al dotar a la judicatura de menor intervención e injerencia de otros poderes (Guarnieri 1994, 248). Además, debemos recordar que, en relación con la judicatura ordinaria, la Suprema Corte sería un actor externo. Ello se acentúa con la propuesta abonada en este artículo que difumina el número de órganos que participan en la integración del Consejo, restando incentivos a una politización desmedida porque las nominaciones judiciales internas serían incapaces de ejercer un control efectivo del órgano per se. Tómese en cuenta que la elección puede ser combinada con factores atenuantes que disminuyan la polarización de las corrientes internas de la judicatura. Por ejemplo, podría combinarse un porcentaje de elección interna con métodos como la insaculación (Benvenuti 2020, 24-34) para disminuir los efectos de métodos electivos puros (más aún si se recuerda que el modelo mexicano tiene experiencia con el método de insaculación).

Por otro lado, los actuales consejeros designados por el Senado y el Ejecutivo parecen permitir una sana conformación plural al CJF y brindan perspectivas diversas a las de los propios miembros del Poder Judicial. La existencia de miembros externos al CJF puede generar control y moderación profesional, así como apertura al exterior para impedir corporativismo y clientelismo judicial (Fix-Fierro 2020, 221 y 222).

Las mismas reflexiones pueden vestirse respecto al consejero nombrado por el Ejecutivo, cuya participación podría ser cuestionada por la alta posibilidad de que prevalezcan criterios de oportunidad política más que jurídica en sus designaciones. Aquí dejamos constancia de que la "politización" de un órgano no necesariamente tiene un sentido peyorativo. Indudablemente, el nombramiento de ministros de la Suprema Corte y de altos cargos como los consejeros de la judicatura, siempre tendrá un contenido político, cuya naturaleza es comprensible. ${ }^{10}$

10 David Law ha puesto sobre la mesa que la acusación de "politización" en el nombramiento de jueces es matizable dado que tales nombramientos son inherentemente de tipo político y, por tanto, debe profundizarse en problemas específicos derivados de la injerencia política. Para el caso norteamericano (proposición presidencial y ratificación de una comisión senatorial), Law identifica tres problemas, a saber: 1) un excesivo énfasis en la ideología de los candidatos — fuerte escrutinio ideológico - ; 2) el nombramiento de jueces ideológicamente extremos y 3 ) las imposibilidades del sistema para poder realizar las designaciones en tiempo y de forma eficiente (Law 2005, 500). Law sustituye el amplio concepto de "politización" por el concepto mucho más concreto de "escrutinio ideológico". 
Esta revista forma parte del acervo de la Biblioteca Jurídica Virtual del Instituto de Investigaciones Jurídicas de la UNAM

El problema real ocurre cuando los partidos políticos pretenden directamente, por medio de sus nombramientos, mantener una influencia en el órgano nombrado. En tales casos, las consideraciones políticas de influencia priman sobre la calidad de los nombrados, lo que ha llevado a propuestas de establecer cuotas de investigadores o catedráticos de carrera en el CJF mexicano (Alto Comisionado de las Naciones Unidas para los Derechos Humanos en México 2003, 12 y 13).

En el caso mexicano, mayor problema ha suscitado, como en general en el caso de nombramientos parlamentarios (el caso español es analizado por Pauner Chulvi 2003, 62-70), los nombramientos realizados por el Senado, que ocasionalmente han presentado retrasos y visos del conocido problema de la lotizazzione, un fenómeno que parece ser connatural a la elección parlamentaria de cargos públicos y al estado de partidos (García Costa 2009, 170).

En resumen, tomando en cuenta la propuesta esbozada de un Consejo formado por 16 integrantes, podría tenerse un CJF con la siguiente conformación: 1) 8 consejeros de origen judicial electos por jueces y magistrados en un sistema interno que garantice una sana proporción a la conformación de jueces, magistrados de tribunal unitario y magistrados de circuito; 2 consejeros nombrados por la Suprema Corte, entre los cuales no podrían figurar ministros; 4 consejeros nombrados por el Senado, y 2 consejeros nombrados por el Ejecutivo. Estos consejeros nombrarían a su propio presidente.

Duración. Un último factor que podría revisarse es la duración de los consejeros. Los consejeros tienen una duración de 5 años en su periodo y no son reelegibles (artículo 100 constitucional). El presidente de la Corte, al ser presidente nato del CJF, tiene por periodo de designación el de la propia Presidencia de la Suprema Corte (4 años, de acuerdo con el artículo 97 constitucional). Es decir, su desempeño en el segundo órgano está ligado a ostentar la calidad de presidente del primero.

Una posible reforma sería la ampliación del periodo a 8 años. Ello contribuiría a garantizar una mayor continuidad en el trabajo técnico de la judicatura y alejaría la designación de los consejeros de la judicatura de la arena política de las renovaciones parlamentarias y presidencial. Dentro del incremento del plazo, debe conservarse el modelo escalonado, cuya ausencia en el sistema español, puede también haber contribuido a la falta de "memoria histórica" (Aguiar de Luque 2008, 1986) del periodo 
Esta revista forma parte del acervo de la Biblioteca Jurídica Virtual del Instituto de Investigaciones Jurídicas de la UNAM

anterior y cuya reforma en México, podría contribuir a cambios drásticos de criterio que deben ser evitados.

\section{Directores y orquestas: la elección del presidente del CFF}

Otro aspecto de indudable trascendencia para garantizar la independencia e imparcialidad del CJF es la presidencia del órgano. Por más virtuosos que sean sus intérpretes, una orquesta precisa, necesariamente, de un buen director para que las melodías aisladas se conviertan en música de cámara. La partitura formada por el conjunto del artículo 100 constitucional en conjunción con las previsiones relativas de la LOPJF nos presenta a un director de orquesta predeterminado: el presidente de la Suprema Corte de Justicia.

Este estudio afirma que este diseño no es el adecuado. Tal determinación quizá pudiera, bajo un análisis superficial, parecer semejante a la presidencia de derecho otorgada al presidente del Tribunal Supremo en el Consejo General del Poder Judicial español. La situación no es comparable. El presidente del Tribunal Supremo español pertenece a un órgano administrado, a su vez, por el Consejo General del Poder Judicial (a diferencia de la Suprema Corte mexicana ajena a esta administración). Además, los vocales de origen judicial en el caso español no han sido nombrados por el Tribunal Supremo (el Consejo nombra a los jueces y no los jueces al Consejo). ${ }^{11}$ Más aún, el presidente del Tribunal Supremo ha sido nombrado a propuesta del propio Consejo con lo cual, materialmente éstos han elegido a su presidente al elegir presidente del Tribunal Supremo. ${ }^{12}$ La amplia composición del Tribunal Supremo español (5 salas y un

11 Recordemos que el Consejo General del Poder Judicial español propone a todos los miembros del Tribunal Supremo y a 2 de los 12 miembros del Tribunal Constitucional.

12 "El Presidente del Tribunal Supremo será nombrado por el Rey, a propuesta del Consejo General del Poder Judicial, en la forma que determine la ley" (artículo 123.2 de la CE). Ahora bien, el artículo 556 de la LOPJ dispone "El Consejo General del Poder Judicial estará integrado por el presidente del Tribunal Supremo, que lo presidirá, y por veinte Vocales, de los cuales doce serán Jueces o Magistrados en servicio activo en la carrera judicial y ocho juristas de reconocida competencia”. Es decir, existe un matiz ligerísimo. Se es elegido presidente del Supremo y, por ende, presidente del Consejo y no viceversa" (Lucas Murillo de la Cueva 2017, 354). Fernández Riveira (2016,377) afirmó sobre la situación que estos recíprocos nombramientos son "Un hilo conductor de legitimidades 
Esta revista forma parte del acervo de la Biblioteca Jurídica Virtual del Instituto de Investigaciones Jurídicas de la UNAM

total de 64 magistrados) y el hecho de que el Tribunal Supremo no sesione nunca en Pleno, nos lleva a pensar que su presidente sí puede dedicarse a tareas administrativas.

La diferencia con la Corte mexicana de 11 ministros es absolutamente notable. El modelo español no es trasladable a la realidad mexicana porque, de hecho, el modelo español es una mezcla material de presidencia electiva y presidencia de derecho. Inclusive con lo reseñado anteriormente, en España se ha propuesto abiertamente separar las elecciones y que sean los propios vocales quienes elijan al presidente del Consejo (Íñiguez Hernández 2012a, 106-108 e Íñiguez Hernández 2006, 269-312).

En Italia, por ejemplo, existe una automática presidencia de derecho por parte del presidente de la República (que no es el presidente del gobierno). También aquí las diferencias son evidentes en tanto el presidente italiano, como jefe de Estado, es (siempre en teoría) símbolo de unidad y defensor de la Constitución (Luciani 2020, 9), aunque no han faltado críticas y recelo a sus funciones en el CSM (Martines 2010, 427-428), lo que explica por qué el vicepresidente del Consejo italiano ha jugado un papel más relevante de lo que pudiera pensarse (De Vergottini 2000, 287-313). Nuestro Ejecutivo federal se asemeja mucho más a su presidente del gobierno que al presidente della Repubblica (aunque ejerza ambas funciones).

En la controversia constitucional 81/2017 la Suprema Corte llegó inclusive a interpretar respecto a un Consejo de la Judicatura local (no regulado por la Constitución federal) que resultaba inconstitucional prohibir que la misma persona presidiese el Consejo de la Judicatura y el Supremo Tribunal de Justicia de una entidad federativa lo que parece, al menos, cuestionable.

En el ámbito federal, mantener el método actual coadyuva a subordinar el CJF a la Suprema Corte y tanto Melgar Adalid (2012, 347 y 2008) como Fix-Zamudio $(2006,268)$ han visto con recelo esta doble presidencia. La coexistencia de un ministro presidente tanto de la Corte como del CJF con consejeros que desempeñan cargos de jueces o magistrados en rangos inferiores es atípica.

El modelo no fomenta deliberación ni intercambio de ideas, pues se antoja bastante complejo que magistrados jerárquicamente en órganos

preocupante que va y viene del Consejo al Supremo, y que teje entre nombramientos y competencias una sutil tela de araña". 
Esta revista forma parte del acervo de la Biblioteca Jurídica Virtual del Instituto de Investigaciones Jurídicas de la UNAM

inferiores disputen en un plano de igualdad las propuestas o determinaciones del presidente del máximo órgano, cabeza jerárquica del poder en que se desempeñan. Como ha argumentado recientemente la doctrina mexicana (Fix-Fierro 2018, 34), la estructura jerárquica del Poder Judicial se traslada al CJF en la coexistencia presidente-consejeros de origen judicial. Fix-Fierro $(2018,34)$ refirió que "ni la unidad institucional ni la supremacía de la cabeza del Poder Judicial exigen necesariamente la acumulación de funciones directivas en una sola persona, pues ello disminuye la eficacia en su desempeño, obstaculiza la especialización y favorece el ejercicio personal del poder".

En suma, concentrar el poder en el presidente de la Suprema Corte puede ir en detrimento de una verdadera autonomía del CJF (Melgar 2008, 82). La dualidad de presidencias, más que fomentar el autogobierno judicial, puede enfatizar la distribución jerárquica del poder en la judicatura en la forma de la personalización (Bobek y Kosar 2013, 14). En la actualidad, la Presidencia dual subordina al Consejo, sobrecarga a la Suprema Corte y no necesariamente garantiza siquiera representatividad de la judicatura, pues el presidente de la Corte podría no provenir de carrera judicial, como en el actual caso del ministro Zaldívar. Por tanto, disentimos de las opiniones de quienes han dicho que esta dualidad es lógica por el entendimiento de las necesidades de la judicatura por el presidente de la Corte (del Rosario 2017, 1564). Entender a la Suprema Corte o ser miembro de ella (inclusive presidiéndola), no conlleva indefectiblemente a conocer a la judicatura federal.

Por las razones mencionadas, parece preferible que sea el propio Consejo de la Judicatura quien escoja al presidente. Esta Presidencia no tiene necesariamente que coincidir con el presidente de la Corte, tanto por razones técnicas como de carga administrativa. Incluso debemos replantearnos si debe el presidente de la Suprema Corte pertenecer al CJF del todo. La respuesta más probable es negativa.

\section{Los límites de la inatacabilidad}

Finalmente, como parte de un análisis de la autonomía del CJF debemos considerar la definitividad de sus decisiones. ¿Cuándo es posible revisar una decisión del CJF? ¿Qué tipo de decisiones deben revisarse? Y, más importante aún para su autonomía, ¿quién puede revisarlas? 
Esta revista forma parte del acervo de la Biblioteca Jurídica Virtual del Instituto de Investigaciones Jurídicas de la UNAM

La inicial configuración constitucional en 1994 había previsto que las decisiones del CJF fueran definitivas e inatacables. Sin embargo, la interpretación de la Corte no dudó en subordinar sus decisiones al escrutinio producto del juicio de amparo a pesar del texto expreso de la Constitución. En 1999, una reforma constitucional clarificó la posibilidad de revisar las decisiones del CJF por parte de la Corte.

A partir de 1999, la Suprema Corte puedo revisar la práctica totalidad de actuaciones esenciales del CJF o solicitar su ejercicio (históricamente lo analiza Rivas Acuña 2011, 164-183). Podríamos subdividir el análisis en dos aspectos de revisión principales, a saber, 1) revisión de acuerdos generales y 2) revisión de decisiones de designación, adscripción, ratificación y remoción de magistrados y jueces.

En primer término, la extinta facultad de revisión de acuerdos generales resultaba peculiar. Previo a la reforma de 2021, la Suprema Corte podía revocar la expedición de los acuerdos generales del CJF por una mayoría calificada de 8 votos (artículo 100 constitucional), lo que hizo que algunos autores calificaran la facultad del Consejo de emitir acuerdos generales como "subordinada” a la Suprema Corte (Sánchez Velarde 2017, 1582). La revisión del dictado de acuerdos generales resultaba ciertamente incompatible con una garantía de autonomía del CJF porque dicha revisión no implicaba ya una lectura desde el marco jurídico, sino de la oportunidad política de organización del Poder Judicial. Esta facultad fue ejercida en dos ocasiones (Pérez Dayán 2020,616) en las que el presidente de la Corte se declaró impedido para participar en la discusión por el obvio conflicto de intereses de presidir al órgano que emitió el acuerdo y al órgano que discutía la revisión de dicho acuerdo general.

La reforma constitucional de 2021 eliminó esta facultad de revisión. Esto es, la Suprema Corte no podrá revisar la actuación del CJF en la expedición de sus acuerdos del todo. Para ello, la iniciativa primaria que desembocó en la reforma de 2021 esgrimió dos argumentos. Por un lado, sostuvo que permitiría hacer más expedito el cumplimiento de los acuerdos. Por el otro, afirmó que implicaría permitirle a la Corte concentrar su atención en las funciones perfiladas hacia un Tribunal Constitucional.

Ciertamente la reforma fue positiva en este aspecto. No existe una razón sistémica que conceptualmente justifique la posibilidad de revisión de acuerdos del CJF por parte de la Suprema Corte en un plano íntegro de política judicial. Aunado a ello, tal revisión resultaba incompatible con 
Esta revista forma parte del acervo de la Biblioteca Jurídica Virtual del Instituto de Investigaciones Jurídicas de la UNAM

una visión de la Corte como Tribunal Constitucional material. Una razón adicional, no considerada en la iniciativa, podría haber sido que eliminar tal facultad coadyuvaría a aminorar la dependencia abierta del CJF a la Suprema Corte para garantizar una mayor autonomía y alejarla de un forzado alineamiento ideológico con la propia Corte. Por tanto, la nueva configuración constitucional tras la reforma de 2021 implicó una mejora frente al escenario regente en el periodo 1999-2020.

Por lo que respecta a la histórica facultad de revisión de decisiones de designación, adscripción, ratificación, y remoción de magistrados y jueces, el escenario ha cambiado parcialmente a raíz de la reforma de 2021.

Previo a la reforma constitucional de 2021, la Suprema Corte podía revisar las decisiones de designación, adscripción, ratificación, y remoción de magistrados y jueces (lo que incluía la posibilidad de revisar cuestiones derivadas de los concursos de oposición para acceder al cargo). Aquí el artículo 100 constitucional hacía una remisión a ley orgánica que el Congreso había empleado para crear el recurso de revisión administrativa (artículo 122 de la LOPJF). El control realizado por vía de revisión administrativanoresultabasóloformal. ${ }^{13}$ Mediante elrecursoderevisiónadministrativa, la Corte evaluaba si las preguntas de los exámenes a magistrado eran claras o cuál era la puntuación que se le debía dar a un aspirante por un curso recibido o impartido.

La reforma constitucional de 2021 manejó un escenario ambivalente y escindió el conjunto de decisiones revisables, dándoles un tratamiento diferenciado. Por un lado, expresamente confirmó la posibilidad de que la Suprema Corte revise toda determinación concerniente a la adscripción, ratificación y remoción de titulares de magistraturas y juzgados de distrito. A pesar de que la Constitución, siempre en teoría, acota dicha revisión a las reglas establecidas constitucional y legalmente, la práctica ha con-

13 Véase la tesis: "REVISIÓn ADMINISTRATIVA. RECURSO CONTRA RESOLUCIONES del Consejo de la Judicatura Federal. Alcance de las atribuciones del Pleno DE la Suprema CORTE DE Justicia de la NACiÓn AL RESOlVERlo"; en la cual expresamente se mencionaba que el Pleno puede analizar todos "los hechos, pruebas, motivos y fundamentos que sustentan la resolución del Consejo de la Judicatura Federal, y determinar si se cumplieron los requisitos exigidos por la Ley, sean de fondo o de forma". Las cursivas son nuestras. Semanario Fudicial de la Federación y su Gaceta, Novena Época, tomo III, marzo de 1996, p. 468. 
Esta revista forma parte del acervo de la Biblioteca Jurídica Virtual del Instituto de Investigaciones Jurídicas de la UNAM

firmado que esta revisión es profunda y más similar a una sustitución en plena jurisdicción que una simple revisión formal rutinaria.

La Suprema Corte sigue erigiéndose, ante una impugnación, en ente decisor último de quiénes serán los titulares de tribunales y juzgados en el caso mexicano y dicha facultad no sólo no se vio intocada, sino confirmada por la reforma constitucional de 2021. Empero, cuestión distinta debe predicarse respecto a las determinaciones concernientes a los concursos de oposición.

La reforma constitucional eliminó el régimen recursivo ante la Corte de estas cuestiones (concursos de designación). Eliminar el recurso sin sustituirlo por algún medio de impugnación, ciertamente hubiese sido dudoso. Como analizaremos en esta sección, la pregunta que han enfrentado países como España, Italia o Polonia no es si debe permitirse la impugnación de estas materias (cuestión pacífica), sino a quién asignar la competencia de resolución. La reforma constitucional de 2021 realizó en este caso un verdadero ejercicio de ingeniería jurídica para lograr una solución intermedia, pero no del todo adecuada.

En primer término, la reforma de 2021 constitucionalizó a uno de los órganos de trabajo del CJF, no presente anteriormente en el texto fundamental, pero existente en la práctica, a saber, el "Instituto de la Judicatura Federal" (al que renombró como "Escuela Federal de Formación Judicial”).

Este órgano es una división administrativa del CJF que se encarga de la capacitación. La reforma constitucional situó al órgano administrativo en la Constitución. Aunado a ello, le confirió en exclusividad, además de los procesos de formación y capacitación, la organización de los concursos de oposición (lo que implica su resolución). Aquí la reforma constitucional precisó que la "designación" de titulares es inimpugnable por recurso alguno, pero permitió que los resultados de los concursos de oposición fueran impugnados ante el Pleno del CJF.

El cambio es claro. Se realizó la transición de un recurso externo (resuelto por otro órgano, en este caso, la Suprema Corte) a un recurso interno (porque será el órgano de trabajo el que resolverá el concurso y el órgano plenario el que solucionará las impugnaciones).

Dotar de competencia al CJF para conocer de impugnaciones atinentes a los concursos de oposición es una propuesta curiosa, aunque no inédita (Trejo 2020, 675). La intención de la reforma de 2021 es loable, pero problemática. Loable por intentar eliminar los conflictos con la Suprema 
Esta revista forma parte del acervo de la Biblioteca Jurídica Virtual del Instituto de Investigaciones Jurídicas de la UNAM

Corte en torno a funciones exclusivamente propias del CJF y por privarle de injerencia en este punto específico. Empero, es problemática porque el recurso ideado puede resultar ilusorio. La constitucionalización del Instituto de la Judicatura Federal bajo el nuevo nombre de "Escuela Federal de Formación Judicial" no cambiará su naturaleza ni estatus. El órgano es una simple división administrativa de trabajo interno jerarquizada y no un cuerpo independiente.

La reforma tampoco dotó a la Escuela Judicial de garantía alguna de su autonomía. Recordemos que la propia reforma mantuvo la estructura actual en la que el CJF puede decidir reglamentariamente su funcionamiento. Además, no hay visos de modificaciones al nombramiento o remoción del titular de la Escuela Federal de Formación Judicial. En síntesis, la Constitución actualmente configura un régimen en que será el propio órgano (CJF) el que organizará el concurso y resolverá las impugnaciones sobre sus resultados (sin perjuicio de que una de sus áreas administrativas esté a cargo de la organización/resultados del concurso y el Pleno del órgano de resolver las impugnaciones).

Sólo por ejemplificar, el "Acuerdo General del Pleno del Consejo de la Judicatura Federal por el que se establece la integración del Comité Académico en el Instituto de la Judicatura Federal" (18/03/2016) confía en su punto primero la designación de los miembros del antiguo Instituto de la Judicatura Federal (11) y su director al Pleno del CJF. Es, por tanto, una designación libre, no constreñida a requisitos gravosos ni con garantías que eviten la remoción. Esta configuración no parece ofrecer pronóstico alguno de que el Instituto se diseñará con la autonomía requerida para cumplir con el requisito formal simple de que el órgano que resuelva el recurso no sea el mismo órgano cuya actuación se impugna. Naturalmente, esta regulación es previa a la reforma constitucional de 2021. Empero, ante la ausencia de modificación en la reciente reforma constitucional, ¿cuáles serían los incentivos para que el CJF realizase alguna modificación para perder control sobre la "Escuela Federal de Formación Judicial" en su nueva denominación? El nombre no cambia su naturaleza. Ante ello, la discusión que se avecinará sobre el funcionamiento del recientemente creado recurso interno será fundamental para evaluar su eficacia, independencia y la compleja relación entre la nueva Escuela Federal y el propio CJF.

Lo anterior muestra que, históricamente, una gran cantidad de decisiones trascendentales del GJF fueron directamente revisables ante la 
Esta revista forma parte del acervo de la Biblioteca Jurídica Virtual del Instituto de Investigaciones Jurídicas de la UNAM

Corte no sólo por criterios de legalidad, sino también de oportunidad política. El choque frontal de criterios administrativos se encontraba siempre destinado a inclinarse en favor de la Corte. Si la Suprema Corte no era capaz de imponer su opinión presidiendo el órgano y designando a los consejeros de origen judicial, aún retenía la facultad de simplemente anular los acuerdos generales privilegiando así su visión del modo de ejercer la administración de justicia. La reforma constitucional de 2021 introdujo importantes matices al debate al eliminar la facultad de revocación de acuerdos y limitar el número de determinaciones del CJF impugnables ante la Corte (creando un recurso interno frente al Consejo respecto a los concursos de oposición) aunque no parece que se hayan resuelto todas las problemáticas.

Debe recordarse que el debate sobre la posibilidad de impugnación de actos de los consejos de la judicatura se da en un plano procedimental y no sustantivo. Esto es, no existe un debate respecto a la conveniencia de permitir su control (cuestión pacífica), sino sobre el sujeto controlador y el alcance de la revisión.

En esa línea, Italia y España contemplan la revisión de la legalidad de tales actuaciones por su jurisdicción administrativa. ${ }^{14} \mathrm{El}$ caso de Polonia es peculiar en tanto, inicialmente, el control de las resoluciones del KRS (Consejo de la Judicatura) se concibió por parte del Supremo Tribunal Administrativo para posteriormente modificarse ${ }^{15}$ en la Ustawa o Krajowej Radzie Sadownictwa del 12 de mayo de 2011 a efectos de permitir el control por la Suprema Corte, órgano que es distinto al Tribunal Constitucional (Sułkowski, 2012, 119).

Todos los ordenamientos tienen en común que existe un control sobre la actuación de los consejos de la judicatura. Sin embargo, ninguno de ellos encomienda tal tarea directamente al Tribunal Constitucional, que es la función materialmente desempeñada por la Suprema Corte en México, esto es, Italia y España (López Guerra 2002, 20) a la jurisdicción contencioso administrativo y Polonia a la Suprema Corte (Sługocki 2012, 421-423). En los ejemplos de derecho comparado, los respectivos consejos

14 En el caso de Italia, tal control fue confirmado por la Corte Constitucional en la Sentencia 419/1995.

15 Varias decisiones motivaron dicha reforma. En particular, puede citarse la sentencia del Tribunal Constitucional polaco K 62/07. De igual forma, las sentencias SK 43/06, SK 57/06 y K 40/07. 
Esta revista forma parte del acervo de la Biblioteca Jurídica Virtual del Instituto de Investigaciones Jurídicas de la UNAM

también colaboran directamente en el nombramiento de los órganos controlados, a excepción de la magistratura administrativa especial en Italia.

México ha configurado un modelo curioso donde la Suprema Corte se debate entre ser el máximo garante de la constitucionalidad, pero al mismo tiempo conservar atribuciones de legalidad. ¿Era necesario preservar la facultad de la Suprema Corte de controlar las decisiones del CJF sobre adscripción, ratificación y remoción de titulares de órganos jurisdiccionales? O ¿más que una tutela de la legalidad de las decisiones era una forma de establecer la prevalencia de la Corte?

Cuestionar el control depositado en la Suprema Corte no significa defender una postura que exente de control las actuaciones del Consejo, pues los órganos constitucionales no pueden estar exentos de control (Carpentier 2005, 69). Sin embargo, a pesar de que el control de sus decisiones despierte fricción y polémica doctrinal (López Aguilar 2017, 684), sí implica replantearse si no es posible encontrar una instancia más idónea para ello.

Las anteriores reformas que se han propuesto y las reflexiones vertidas en torno a la posición y funciones del CJF deben considerarse un marco integral y no propuestas que aisladamente puedan implementarse. Por ejemplo, permitir el nombramiento propio del presidente del Consejo, pero mantener como consejero de derecho al presidente de la Suprema Corte y la forma en que se configura actualmente el recurso de revisión parece carecer de sentido al permitir retener a la Corte el control del CJF y perfilar una elección que no incidirá en la autonomía del órgano. Debe realizarse un análisis integral del CJF fuera del cortoplacismo de cambios cosméticos.

\section{5. ¿Ha pasado el peligro? La nueva facultad de "concentración” del CfF}

Los consejos de la judicatura tienen por finalidad garantizar la independencia judicial (Carpizo 2000, 2012). A pesar de que prototípicamente se busca asegurar tal garantía frente a actores externos, la independencia judicial requiere, de igual forma, que ésta se predique frente al propio Consejo. Un Consejo de la Judicatura con facultades excesivas o discrecionales frente a los juzgadores puede generar incentivos para convertirse en fuente de indeseables injerencias en la judicatura a la que debe administrar, pero no "controlar". 
Esta revista forma parte del acervo de la Biblioteca Jurídica Virtual del Instituto de Investigaciones Jurídicas de la UNAM

La reforma constitucional de 2021 dotó al CJF de la facultad de "concentrar" asuntos en órganos jurisdiccionales específicos para que conozcan de hechos que constituyan violaciones graves a los derechos humanos. ${ }^{16}$ Expresamente la Constitución establece que esta facultad será una excepción a los principios de turno y competencia. Sea o no un precepto operativo de distribución competencial, se creyó conveniente consagrar una restricción constitucional específica.

En la iniciativa del proyecto de reforma se proponía inicialmente dotar al CJF de la facultad de "designar" a juzgadores específicos. Esta facultad parecía implicar permitirle la elección de juzgadores en concreto, violando la garantía del juez natural. La iniciativa sólo justificó este aspecto lacónicamente señalando que esto "garantiza la concentración de los asuntos, para dar una solución coherente y expedita a casos de trascendencia social". La iniciativa era controversial.

El turno y la competencia son garantías de independencia para los juzgadores al asegurar que los asuntos que les sean encomendados no provengan de una decisión específica, sino que sean predeterminados por reglas de distribución territorial o aleatorias (turno). La imposibilidad que tienen el Parlamento, gobierno e, inclusive, el propio Poder Judicial de designar a un órgano específico para que resuelva un caso, es una garantía para los justiciables de la resolución de asuntos porque evita que esta selección se realice con criterios ideológicos o políticos.

La iniciativa de reforma constitucional proponía facultar al CJF a tomar una determinación que, más allá de administrar al Poder Judicial, podía permitirle conducirlo. El lenguaje de la iniciativa implicaba la designación ad hoc de juzgadores para casos específicos. Ciertamente podría alegarse que esta facultad le hubiera permitido al CJF elegir jueces cuya visión y apertura llevaran a una mejor impartición de justicia, pero también podría haberle permitido lo opuesto: preferir encomendar determinados asuntos a juzgadores específicos en línea con una visión concreta.

16 La reforma al artículo 100 estableció el siguiente texto actual en la Constitución tras la reforma de 2021: "El Consejo de la Judicatura Federal podrá concentrar en uno o más órganos jurisdiccionales para que conozcan de los asuntos vinculados con hechos que constituyan violaciones graves de derechos humanos. La decisión sobre la idoneidad de la concentración deberá tomarse en función del interés social y el orden público, lo que constituirá una excepción a las reglas de turno y competencia”. 
Esta revista forma parte del acervo de la Biblioteca Jurídica Virtual del Instituto de Investigaciones Jurídicas de la UNAM

La terminología constitucional finalmente adoptada (concentración) debe entenderse como una herencia atenuada del proyecto original. Las atenuantes reducen, pero no eliminan las dudas. ¿Vulnera la nueva redacción el derecho al juez natural o el cambio de "designación" a "concentración" ha eliminado las problemáticas?

La jurisprudencia de la Corte Interamericana ha sido enfática en señalar el derecho a un juez natural. Si bien mayormente se ha emitido jurisprudencia en torno a tribunales militares, ha señalado que el artículo 8.1 de la Convención garantiza un derecho a ser juzgado por tribunales ordinarios competentes (Feuillade 2009, 29). Por ejemplo, en el caso Ivcher Bronstein vs. Perú (2001) la Corte Interamericana sostuvo que "al crear Salas y Juzgados Transitorios Especializados en Derecho Público y designar jueces que integraran los mismos" el Estado había vulnerado el derecho de una persona a la jurisdicción previsto en el artículo 8.1 de la Convención.

Se ha sostenido que el derecho al juez ordinario comprende tanto la constitución del órgano jurisdiccional (la existencia de éste previo al proceso) como la competencia lato sensu del órgano. La competencia es el respeto a los criterios correspondientes para identificar cuál órgano jurisdiccional es el encargado de resolver un asunto atendiendo al territorio, materia o cuantía (Díez-Picazo 1999, 81). La reciente reforma constitucional incide directamente en el segundo punto. El CJF podrá decidir ex-post cuál es el órgano apropiado para concentrar asuntos tomando en cuenta el "interés social" y el "orden público".

Guando exista una amplia variedad de jugadores dentro de los cuales elegir debemos preguntarnos: ¿cuál será el criterio orientador del CJF para decidir al órgano apropiado para "concentrar" ante la variedad de juzgadores? ¿El criterio del juzgador en casos pasados? ¿La formación del juzgador? ¿El tipo de jurisprudencia que ha emitido? ¿La especial sensibilidad de un titular a cierto tipo de casos? El uso de cualquiera de estos criterios anticiparía que el Consejo intenta, mediante la asignación de ese órgano como "concentrador", anticipar un probable resultado.

Como segundo problema de la misma propuesta, puede señalarse la gran amplitud de la hipótesis detonante. El término "violaciones graves de derechos humanos" es altamente ambiguo y, dada la ausencia de mecanismos de control sobre esa determinación, permite un manejo discrecional de la facultad. Más aún, los conceptos de "interés social" y "orden 
Esta revista forma parte del acervo de la Biblioteca Jurídica Virtual del Instituto de Investigaciones Jurídicas de la UNAM

público" tampoco acotan la facultad a parámetros definidos. Al carecer de estándares objetivos, la reforma constitucional actualiza un amplio margen discrecional al CJF.

La excepción expresa "a las reglas de competencia y turno" (artículo 100 constitucional), contenida en la flamante reforma constitucional, deberá ser analizada a la luz del artículo 8.1 de la Convención Americana sobre Derechos Humanos y su interpretación por la Corte Interamericana (competencia, independencia, imparcialidad y establecimiento con anterioridad en la ley) (Rodríguez 1998, 1316). Turno y competencia, en suma, son garantías de independencia e imparcialidad para el justiciable.

No debe olvidarse tampoco que el artículo 13 de la Ley de Amparo contenía ya previo a la reforma una disposición parecida, aunque con importantes matices. Dicho precepto faculta al CJF a petición de cualquiera de las partes (si se señalan actos reclamados distintos, pero con perjuicios análogos o se reclama el mismo acto u omisión), a la "concentración de todos los procedimientos ante un mismo órgano del Poder Judicial de la Federación según corresponda". Esta facultad ha sido incluso desarrollada por el GJF en su acuerdo general 26/2015. A este tipo de desplazamiento competencial se le conoce con frecuencia como competencia por conexidad. Por ello, quizá pudiera formularse un argumento en el sentido de que la matización de la iniciativa original (modificando la terminología de "designar" a "concentrar") alude a una regla de competencia por conexidad. Sin embargo, el argumento no es del todo sólido. La competencia por conexidad forma parte de las competencias prefijadas, por lo que resultaba innecesario, si esa era la intención, precisar que dicha concentración exceptúa expresamente las reglas de competencia y turno (bastaba con establecer un desarrollo legal y la conexidad pasaría a formar parte del entramado competencial previsto con antelación al conflicto y sus reglas podrían prefijarse con más detalle limitando márgenes discrecionales).

Más aún, si la conexidad ha sido incorporada a procesos federales como el amparo en aplicación supletoria del Código Federal de Proce-

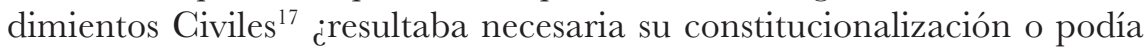
hacerse en ley secundaria al ser una reforma inocua? ¿Era necesario rei-

17 Véase la jurisprudencia P./J. 24/2015 (10a.), de rubro "ACUMULACiÓN DE JUICIOS DE AMPARO INDIRECTO. PROCEDIMIENTO CUANDO SE ENCUENTRAN RADICADOS ANTE 
Esta revista forma parte del acervo de la Biblioteca Jurídica Virtual del Instituto de Investigaciones Jurídicas de la UNAM

terar constitucionalmente un tema pacífico? ${ }^{18}$ Por otro lado, si se pretendía establecer una conexidad específica para procesos no constitucionales, ¿no resultaba más sencillo reformar el Código Federal de Procedimientos Civiles, el Código Nacional de Procedimientos Penales y las demás normas procesales sin necesidad de establecer una restricción constitucional expresa al derecho de competencia y turno? ¿O a qué tipo de procesos naturales se refiere la Constitución? El establecimiento de restricciones constitucionales expresas siempre permiten avizorar que la intención del texto no es inocua.

Dos posibilidades son ineludibles de considerar: o su constitucionalización resultaba ociosa y no trascendental o los matices realizados fueron una forma de salvar una facultad cuya formulación inicial era demasiado polémica y cuyas posibilidades de ejercicio aún están por verse.

En conclusión, previo a la reforma constitucional de 2021, la configuración del CJF ciertamente podía despertar dudas sobre los procedimientos disciplinarios a los jueces, pero no existía un debate directo sobre la injerencia del Consejo en la asignación de asuntos o procesos específicos. La reforma constitucional, lejos de solucionar un problema de independencia judicial, abrió nuevas interrogantes.

La forma en que se utilice la nueva facultad determinará si se ha creado una redundante regla de competencia inofensiva (cuya constitucionalización resultaba entonces innecesaria) o si la facultad da pie a usos controversiales. Sin duda, la independencia judicial interna, predicable frente al CJF, será un debate abordado en el constitucionalismo mexicano de cara al futuro ejercicio de esta nueva facultad.

\section{CONCLUSiOnes}

A lo largo de este breve estudio comparado se han analizado diversos aspectos del CJF que garantizan su subordinación y dependencia a la Suprema Corte de Justicia de la Nación. Tal modelo debe verse con recelo

EL MiSMO JUZGADOR FEDERAL", visible en la gaceta del Semanario fudicial de la Federación, Libro 22, tomo I, septiembre de 2015, p. 19.

18 Este pareció ser el entendimiento de diversos senadores en el debate correspondiente. Véase la sesión ordinaria vespertina de la Cámara de Senadores del 27 de noviembre de 2020. Disponible en: https://bit.ly/3ahEpgR (última consulta 28/01/2021). 
Esta revista forma parte del acervo de la Biblioteca Jurídica Virtual del Instituto de Investigaciones Jurídicas de la UNAM

en tanto la paulatina evolución de las funciones de la Suprema Corte la ha llevado cada vez más a asemejarse a un Tribunal Constitucional material.

Si las atribuciones de legalidad han ido desapareciendo con cada vez mayor frecuencia del marco de la Suprema Corte, la retención de una desmedida influencia en la administración de justicia no es compatible ni con una Suprema Corte más cercana a un Tribunal Constitucional ni con un Consejo autónomo.

Existe una gran injerencia de la Corte en el CJF en la forma de la Presidencia de derecho del órgano, en la designación de sus miembros o la posibilidad de revisar sus decisiones en materia de adscripción, ratificación y remoción de titulares de órganos jurisdiccionales. El modelo se ha mostrado, de esta forma, titubeante. No ha conferido abiertamente la administración del Poder Judicial a la Suprema Corte, pero tampoco se ha construido un GJF fuerte e independiente lejos del alcance de la Corte. Esta ambivalencia de modelos produce un resultado confuso. Pareciera ser que el constitucionalismo mexicano no ha generado un consenso en torno a qué CJF queremos.

La reforma constitucional de 2021 no ha dado una respuesta a esta interrogante y ha abierto, en cambio, más preguntas. La reforma intentó atender algunos de los problemas históricos del CJF mexicano. Parte de las soluciones ofrecidas son el incremento de la autonomía del Consejo en torno a la irrevocabilidad de sus acuerdos y el esfuerzo - no completamente exitoso - de diseñar un procedimiento de impugnación de problemáticas atinentes a los concursos judiciales.

Sin embargo, la reforma constitucional de 2021, en su silencio, confirmó aspectos criticables del régimen constitucional mexicano. La Constitución permanece silente sobre una potencial autonomía con un correlato de vías competenciales, la Presidencia del Consejo bajo control de la Suprema Corte, la influencia de la Corte en la elección de consejeros judiciales, el reducido número de consejeros o el control por parte de la Corte de las determinaciones del CJF en adscripción, remoción y ratificación de juzgadores vía recurso de revisión administrativa (no compatible, por cierto, con las funciones de Tribunal Constitucional de la Suprema Corte). Se perdió, como ya ha acontecido anteriormente (Cárdenas Gracia 2013, 385), otra oportunidad de realizar una reforma integral al CJF y no cambios cosméticos menores. Por otro lado, las soluciones a los pocos problemas aborda- 
Esta revista forma parte del acervo de la Biblioteca Jurídica Virtual del Instituto de Investigaciones Jurídicas de la UNAM

dos, no sólo son perfectibles, sino que generan nuevos problemas potenciales, como hemos analizado.

Un CJF con una posición institucional fortalecida podría generar mejores resultados. La reforma de 2021, con los cambios adoptados, parece haber puesto freno, al menos temporal, al debate de modificaciones al CJF. Empero, la discusión persiste. El CJF no debería formar parte del Poder Judicial, la Suprema Corte no debe necesariamente nombrar a todos los consejeros de origen judicial y, en definitiva, la Presidencia del órgano debería ser una decisión interna del propio CJF. Tanto por razones de garantía institucional, de carga laboral del presidente de la Suprema Corte y futura relación en la revisión de las decisiones, éste no es la persona más idónea para presidir, a su vez, al CJF y quizá, probablemente, pudiésemos replantearnos si debe integrarlo del todo.

En el abanico de derecho comparado existen muchos, sistemas que emplean consejos de la judicatura para garantizar la función administrativa del Poder Judicial, pero también hay sistemas que prescinden de ellos. Alemania ${ }^{19}$ e Inglaterra (Fernández Riveira 2020, 91) son claros ejemplos de sistemas que pueden trabajar designando jueces con participación de sus ministerios o creando comisiones de participación dual para nombrarlos.

¿Por qué estos sistemas, que permiten una abierta participación del Ejecutivo u otros poderes, pueden llegar a producir resultados aceptables y designaciones no controvertidas? La respuesta tiene que ser, necesariamente, que el comportamiento responsable de sus actores tiene un mayor peso que el de los diseños institucionales. Son las personas quienes hacen que funcionen las instituciones y no las instituciones quienes siempre pueden orientar el comportamiento de los sujetos, aunque ésta no sea una excusa para mejorar los siempre perfectibles diseños.

19 Mediante los "Richterwahlausschüsse" en los Länder, ya previstos en el artículo 98.4 de la Ley Fundamental de Bonn. Para el caso de los tribunales de la Federación, la regla regente es similar, prevista en el artículo 95.2 GG. Frecuentemente se argumenta que este comité puede fortalecer su legitimidad democrática (Heusch 2011, 2058). La normativa alemana trata de promover al juez de carrera a la vez que intenta evitar tensiones democráticas, incluyendo a los ministerios y al Senado en la composición del comité de selección (Jarass y Pieroth 201 1, 987). Además, en la Comisión de selección, usualmente participa el ministro cuyo Ministerio (secretaría) se encarga de la materia sustantiva correspondiente al juzgado con la plaza vacante (Meyer 2012, 757). El mismo modelo predomina en Austria por influencias recíprocas (Öhlinger 2012, 274).

Esta obra está bajo una Licencia Creative Commons 
Esta revista forma parte del acervo de la Biblioteca Jurídica Virtual del Instituto de Investigaciones Jurídicas de la UNAM

Recordemos que, como se ha dicho al respecto de órganos similares en otras latitudes, el Consejo de la Judicatura no es un órgano estrictamente necesario. No es integrante básico de la división de poderes ni un órgano indefectible en el Estado (Íñiguez Hernández 2008, 467). Es posible prescindir de un Consejo de la Judicatura siempre que se ofrezca un modelo alternativo funcional.

En cambio, si la decisión es mantener el modelo de un CJF en México, debemos replantearnos fuertemente su posición institucional y cuestionar si la posición actual del Consejo es la óptima para desempeñar con objetividad, independencia e imparcialidad las funciones que tiene encomendadas y, sobre todo, cuál es la relación óptima que debe tener frente a la Suprema Corte, ante su influencia fundamental en éste.

El CJF debe analizarse en su integridad para sortear los riesgos de la presbicia y fortalecer sus funciones que, correctamente desempeñadas, ayudarán a mejorar la calidad de nuestros juzgadores. El debate sobre su diseño institucional debe ser meditado, cuidadoso y profundo. El ejemplo de España se erige como advertencia de los peligros de configuraciones debatibles (Lucas Murillo de la Cueva 2009, 41 y 42), ${ }^{20}$ incluso si se ha variado sólo uno de sus elementos (designación parlamentaria). En juego está el Poder Judicial que queremos.

20 Aprecia Íñiguez que el Consejo ha tenido en algunas ocasiones verdadero ánimo de incursionar mediante sus actuaciones en el debate político "Que esto haya ocurrido en un órgano creado precisamente para apartar a los jueces de la política refuerza la impresión de desnaturalización y fracaso en su función” (Íñiguez Hernández 2012b, 104). Iñiguez llega incluso a hablar del "fracaso indiscutido en su labor constitucional de garantía". Sin embargo, hay autores medianamente escépticos con esta crítica (Terol Becerra 2003-2004, 645 y 646). Analizar las causas de este "ambiente politizado" en el Consejo General del Poder Judicial en España exceden los propósitos de este trabajo. Únicamente a modo de esbozo, creemos que hay varios factores cuya interrelación han traído estos resultados. Entre tales factores podrían citarse 1) la mutua influencia entre asociaciones judiciales y partidos políticos; 2) la prohibición a los jueces de pertenecer a partidos políticos, tensiones que, canalizadas en las asociaciones judiciales, las han hecho tener quizá un desproporcionado papel protagónico dentro de la judicatura; 3) el inicial recelo a la judicatura heredada del modelo franquista; 4) la designación con el tamiz del escrutinio ideológico del parlamento a los vocales de origen judicial. Estas son algunas de las causas de las tensiones internas del Consejo General del Poder Judicial español. 
Esta revista forma parte del acervo de la Biblioteca Jurídica Virtual del Instituto de Investigaciones Jurídicas de la UNAM

\section{BIBLIOGRAFÍA}

ACKerman, John. 2009. "Repensar la estructura institucional para la rendición de cuentas en el Estado Mexicano". AcKerman, John y AstuDILlo, César (coords.), La autonomía constitucional de la Auditoría Superior de la Federación. México. UNAM, Instituto de Investigaciones Jurídicas.

Aguiar de DuQue, Luis. 2008. "Artículo 122". Casas BaAmonde, María y RoDRÍGUEZ-PIÑEIRO, Miguel (dirs.), Comentarios a la Constitución Española. Toledo. Wolters-Kluwer.

Alto Comisionado de las Naciones Unidas para los Derechos Humanos en México. 2003. Diagnóstico sobre la situación de los derechos humanos en México. México. Mundiprensa.

Astudillo, Cesar. 2019. Derecho procesal constitucional. Estudios sobre la Suprema Corte de Justicia de la Nación. México. Tirant lo Blanch.

BÁEz SiLva, Carlos. 2003. "La Escuela Judicial del Poder Judicial de la Federación”. Reforma Fudicial: Revista Mexicana de Fusticia (2).

BANASZAK, Bogusław. 2009. Konstytucja Rzeczypospolitej Polskiej: Komentarz. Varsovia. G.H. Beck.

Benvenuti, Simone. 2020. "Brevi note sull'affaire CSM: vecchi problemi, ma quali soluzioni?". Osservatorio Costituzionale (1).

BOBEK, Michal y Kosar, David. 2014. "Global solutions, local damages: A Critical Study in Judicial Councils in Central and Eastern Europe". European Legal Studies, Research Paper in Law (7).

CAbellos, Miguel Ángel. 2020. "La reforma inacabada: el Consejo General del Poder Judicial ante su enésima reformulación". Revista Española de Derecho Constitucional (1 18). México.

Cárdenas Gracia, Jaime. 1996. Una Constitución para la democracia. Propuestas para un nuevo orden constitucional. México. UNAM, Instituto de Investigaciones Jurídicas.

CÁrdenas Gracia, Jaime. 2013. "La nueva Ley de Amparo". Cuestiones Constitucionales (29). México.

CARPentier, Élise. 2005. "L'Organe, L'acte et le conflit constitutionnels". Annuaire International de Fustice Constitutionnelle. París.

CARPENTIER, Élise. 2006. La résolution jurisdictionnelle des conflits entre organes constitutionnels. Clermont-Ferrand. Editorial Varenne.

CARPIZO, Jorge. 2000. "Otra reforma constitucional: la subordinación del Consejo de la Judicatura Federal". Cuestiones Constitucionales (2). México. 
Esta revista forma parte del acervo de la Biblioteca Jurídica Virtual del Instituto de Investigaciones Jurídicas de la UNAM

Comisión de Venecia para la Democracia a Través del Derecho. 2007. "Judicial Appointments". Opinión 403/2006. CDL-AD (2007) 028.

Comité de Ministros del Consejo de Europa. 2011. Judges: Independence, efficiency and responsability. Recommendation CM/Rec(2010)12 and explanatory memorandum, Estrasburgo. Council of Europe Publishing.

DíEz-PICAZO, Ignacio. 1999. "El derecho fundamental al juez ordinario predeterminado por ley". Revista Española de Derecho Constitucional (31).

Díez-Picazo, Ignacio. 2018. "Artículo 22”. Pérez Tremps, Pablo y SAINZ, Alejandro (dirs.). Comentario a la Constitución Española. Madrid. Tirant lo Blanch.

Dussauge, Mauricio. 2016. "Organismos constitucionales autónomos y reforma administrativa en México". CARMEN, María del y CEJUdO, Guillermo (eds.). Trayectorias de reformas administrativas en México: legados y conexiones. México. El Colegio de México.

FERnÁndez Riveira, Rosa. 2016. "Nuevos enfoques de la independencia judicial. Dos puntas de Iceberg en la reforma de la Ley Orgánica del Poder Judicial: la Comisión Permanente del CGPJ y el Gabinete Técnico del Tribunal Supremo". Teoría y Realidad Constitucional (38).

FERnÁndez Riveira, Rosa. 2020. “CCómo se nombra discrecionalmente el Poder Judicial? El Consejo General del Poder Judicial y la Judicial Appointment Comission en el Reino Unido. Revista de Derecho Político (107).

Feuillade, Milton C. 2009. "El juez natural en la jurisprudencia de la Corte Interamericana de Derechos Humanos". Revista del Centro de Investigaciones de Filosofia Jurídica y Filosofía Social, (32).

FIX-FierRO, Héctor (ed.). 2018. Ocho propuestas para fortalecer al Poder Fudicial de la Federación y completar su transformación. Una propuesta académica. UNAM, Instituto de Investigaciones Jurídicas.

FIX-FierRo, Héctor. 2020. El Poder del Poder Fudicial y la moderación jurídica en el México contemporáneo. México. UNAM, Instituto de Investigaciones Jurídicas.

FIX-ZAMUDIO, Héctor. 1967. "Reformas constitucionales al Poder Judicial federal". Revista de la Facultad de Derecho de México (65).

FiX-ZAmudiO, Héctor. 2006. "Justicia constitucional y control de legalidad en México". VAladés, Diego y Garbonell, Miguel (coords.). El Estado constitucional contemporáneo. Culturas y sistemas jurídicos comparados (tomo I). México. UNAM, Instituto de Investigaciones Jurídicas. 
Esta revista forma parte del acervo de la Biblioteca Jurídica Virtual del Instituto de Investigaciones Jurídicas de la UNAM

García Costa, Francisco Manuel. 2009. La función electoral del Parlamento. Barcelona. Atelier.

GARCíA RoGA, Javier. 1987. El conflicto entre órganos constitucionales. Madrid. Tecnos.

GARLICKI, Leszek. 2012. Polskie prawo konstytucyjne. Varsovia. Liber.

Garoupa, Nuno y Ginsburg, Tom. 2009. "Guarding the guardians: Judicial Councils and Judicial Independence". The American Fournal on Comparative Law, vol. 57 (1).

Gerpe Ladín, Manuel. 1992. "El Consejo del Poder Judicial". Revista de Derecho Político (36).

GiacobBE, Giovanni. 1994. "Autogobierno de la Magistratura y la unidad de la jurisdicción en el ordenamiento constitucional de la república italiana". Justicia y Sociedad. México, UNAM, Instituto de Investigaciones Jurídicas.

Gómez Colomer, Juan Luis. 2019. "Sobre el nombramiento del presidente y de los vocales del Consejo General del Poder Judicial. Una reflexión desde el sentido común". Teoría y Realidad Constitucional (44).

Gómez Marinero, Carlos Martín. 2008. "Algunas reflexiones en torno al Consejo de la Judicatura Federal en México". Revista Legislativa de Estudios Sociales y Opinión Pública, vol. 4 (8).

Gómez Montoro, Ángel. 1992. El conflicto entre órganos constitucionales. Madrid. Centro de Estudios Constitucionales.

GUARnIERI, Carlo. 1994. "Justice and Politics: The Italian case in comparative perspective". Indiana International \& Comparative Law Review, vol. $4(2)$.

GutiÉRrez, Miguel. 2018. La facultad disciplinaria del Consejo de la fudicatura en México. México. UNAM, Instituto de Investigaciones Jurídicas.

HernánDEZ, Alfonso y CHÁvez, José. 2019. "Las defensorías del pueblo en México como límites al poder”. NARro, Joaquín. Autonomía de los organismos públicos de derechos humanos. México. Comisión Nacional de los Derechos Humanos.

Herrera García, Alfonso. 2005. "Algunas propuestas de reforma a la controversia constitucional en el contexto de la función de jurisdicción constitucional en México". Cienfuegos, David y LóPez, Miguel. Derecho procesal. Estudios en Homenaje a don Forge Fernández Ruiz. México. UNAM, Instituto de Investigaciones Jurídicas. 
Esta revista forma parte del acervo de la Biblioteca Jurídica Virtual del Instituto de Investigaciones Jurídicas de la UNAM

Heusch, Andreas. 2011. "Artikel 98”. Schmidt-Bleibtreu, Bruno y Klein, Franz (coords.). Kommentar zum Grundgesetz. Lavis. Carl Heymanns Verlag.

ÍÑIgUeZ HeRnÁNDEZ, Diego. 2006. "El gobierno del Poder Judicial: Fracaso y remedio del Consejo General y nuevos consejos territoriales". IbARRA, Juan Luis y García, Miguel Ángel (codos.). Poder Fudicial y Unidad Jurisdiccional en el Estado Autonómico. Madrid. Consejo General del Poder Judicial.

ÍÑIGUEZ HeRnÁNDEZ, Diego. 2008. El fracaso del autogobierno judicial. Pamplona. Thomson Civitas.

ÍÑ la Política Judicial”. Jueces para la Democracia (74).

ÍÑiguez HeRnÁNDEZ, Diego. 2012b. "Las funciones ad extra del CGPJ". Aguiar de Luque, Luis (dir.). El gobierno del Poder Fudicial. Madrid. Centro de Estudios Políticos y Constitucionales.

Jarass, Hans y Pieroth, Bodo. 2011. Grundgesetz fiur die Bundesrepublik Deutschland. Kommentar. Munich. Beck.

LAW, David. 2005. "Appointing federal judges: The President, The Senate, and the prisoner's dilemma". Cardozo Law Review, vol. 26 (2). Nueva York.

López Aguilar, Juan. 2017. "El Poder Judicial”. López Garrido, Diego et al. Derecho constitucional comparado. Valencia. Tirant lo Blanch.

López Guerra, Luis. 2002. "Consejo General del Poder Judicial y Política de la Justicia en España". Derecho PUCP, vol. 55 (7).

Lucas Murillo de la Cueva, Pablo. 2009. "A vueltas con el Consejo General del Poder Judicial". Anuario Nuevas Políticas Públicas (5).

Lucas Murillo De la Cueva, Pablo. 2017. "La independencia y el gobierno de los jueces: un debate constitucional". Teoría y Realidad Constitucional (40).

LuCiANI, Massimo. 2020. "Il Consiglio superiore della magistratura nel sistema costituzionale". Osservatorio Costituzionale (1).

Martines, Temistocle. 2010. Diritto costituzionale. Milano. Giuffrè Editore.

Melgar AdAlid, Mario. 2008. "La doble presidencia de la Suprema Corte de Justicia y del Consejo de la Judicatura Federal. Una asignatura pendiente". Ferrer MAGGregor, Eduardo y ZaLdívar, Arturo (coords.), La ciencia del derecho procesal constitucional: tomo XI. México. UNAM, Instituto de Investigaciones Jurídicas. 
Esta revista forma parte del acervo de la Biblioteca Jurídica Virtual del Instituto de Investigaciones Jurídicas de la UNAM

Melgar Adalid, Mario. 2012. La Suprema Corte de Estados Unidos, México, Porrúa.

MEYER, Wolfgang. 2012. "Artículo 95”. Münch, Ingo von (coord.). Grundgesetz Kommentar. Munich, C.H. Beck.

NIETO, Gabriela. 2011. "Órganos constitucionales autónomos y la administración de justicia de las entidades federativas en México". GonZÁLEZ, Manuel y Cienfuegos, David (coords.), Estudios de derecho constitucional local. Coahuila. Congreso de Coahuila.

ÖHLINGER, Theo. 2012. Verfassungsrecht. Viena. Facultas.

OvalLE FAVELA, José. 2011. "La controversia constitucional y los órganos autónomos", Cuestiones Constitucionales (25). México.

Pauner Chulvi, Cristina. 2003. La designación parlamentaria de cargos públicos. Madrid. Congreso de los Diputados.

PÉRez DAYÁn, Alberto. 2020. "La revisión de acuerdos del Consejo de la Judicatura Federal”. Astudillo, César y Cossío, José. Organización y funcionamiento de la Suprema Corte de Fusticia de la Nación. México. Tirant lo Blanch.

Pizoruzzo, Alessandro. 1981. Lezioni di diritto costituzionale. Roma. Il foro italiano.

Rebollar, Yuridia y Rosales, Carlos. 2016. "La experiencia Europea del Consejo de la Judicatura como órgano de Gobierno del Poder Judicial". Revista de la Facultad de Derecho (40).

Rivas AGuña, Israel. 2011. El Consejo de la Judicatura Federal. México. UNAM, Instituto de Investigaciones Jurídicas.

RoDríGuez, Víctor. 1998. "El debido proceso legal y la Convención American sobre Derechos Humanos". Liber Amicorum. Héctor Fix-Zamudio. San José, Secretaría de la Corte Interamericana de Derechos Humanos.

Rosado Iglesias, Gema. 2018. "La Constitucionalización del Gobierno Judicial: Cuarenta años de Consejo General del Poder Judicial, Régimen Actual y Cuestiones Pendientes". Revista de Derecho Politico (1010).

Rosario, Marcos del. 2017. "Comentarios al artículo 100". Cossío, José Ramón (coord.). Constitución Política de los Estados Unidos Mexicanos comentada. México. Tirant lo Blanch.

SAlazAR, Pedro y SALGAdo, Luis. 2009. "Órganos constitucionales autónomos. Una propuesta de reforma”. América Latina. Tendencias y perspectivas. México. UNAM, Instituto de Investigaciones Jurídicas. 
Esta revista forma parte del acervo de la Biblioteca Jurídica Virtual del Instituto de Investigaciones Jurídicas de la UNAM

SÁnchez Velarde, Mónica. 2017. "Comentarios al artículo 100 Constitucional. Párrafo Octavo”. Cossío, José Ramón (coord.), Constitución Política de los Estados Unidos Mexicanos comentada. México. Tirant lo Blanch.

SARNECKI, Paweł. 2009. "Spory kompetencyjne przed Trybunałem Konstytucyjnym", Przyglad Sejmowy, vol. 94(5), Varsovia.

Serra Cristóbal, Rosario. 2013. "La elección de los miembros del Consejo General del Poder Judicial: una propuesta de Consejo más integrador e independiente", núm. 31.

SICARDI, Stefano. 1993. Il conflitto di attribuzione tra Consiglio Superiore della Magistratura e Ministro della Giustiza. Torino. G. Giappichelli editore.

SILVESTRI, Gaetano. 2017. "Consiglio superiore della magistratura e sistema costituzionale". Questione Giustizia (4).

SŁugocki, Janusz. 2012. Prawo Administracyjne: Zagadenienia ustrojowe. Varsovia. Wolters Kluwer.

SoBCZAK, Jacek. 2010. "Krajowa Rada Sądownictwa”. Skrzydło, Wiesław (ed.), Polskie prawo konstytucyjne. Lublin. Verba.

Sotelo, Raigosa. 2017. "Control de la regularidad constitucional (constitucionalidad y convencionalidad)". El Poder Fudicial de la Federación y los grandes temas del constitucionalismo. México. SCJN-UNAM, Instituto de Investigaciones Jurídicas.

SuŁkOwski, Jarosław. 2008. "Uprawnienia Prezydenta RP do Powoływania sędzów", Przyglad Sejmowy vol. 87(4), Varsovia.

SuŁKOwSKI, Jarosław. 2012. "Ustawa o Krajowej Radzie Sądownictwa w kontekście orzecznictwa Sądu Najwyższego, Izby Pracy, Ubezpieczeń Społecznych i Spraw Publicznych". Przeglad Sejmowy, vol. 11(4), Varsovia.

Terol Becerra, Manuel. 1990. El Consejo General del Poder Fudicial. Madrid. Centro de Estudios Políticos y Constitucionales.

Terol Becerra, Manuel. 2003-2004. "Veinticinco años del Consejo General del Poder Judicial". Revista de Derecho Político (58-59).

TORRES, Aida. 2018. "Judicial Self-Government and Judicial Interdependence: the Political Capture of the General Council of the Judiciary in Spain". German Law Fournal, vol. 19(7).

TREJO, José. 2020. "El recurso de revisión en materia de concursos de jueces y magistrados". Astudillo, César y Cossío, José, Organización y funcionamiento de la Suprema Corte de Justicia de la Nación. México. Tirant lo Blanch.

Esta obra está bajo una Licencia Creative Commons

Atribución-NoComercial-SinDerivar 4.0 Internacional, IIJ-UNAM.

Boletín Mexicano de Derecho Comparado, núm. 159, septiembre-diciembre de 2020, pp. 1139-1179. 
Esta revista forma parte del acervo de la Biblioteca Jurídica Virtual del Instituto de Investigaciones Jurídicas de la UNAM

TrujILlo, María Antonia. 1995. Los conflictos entre órganos constitucionales del Estado. Madrid. Congreso de los Diputados.

VÁzQUEz MATA, Marisonia. 2010. "Ampliación de las hipótesis de procedencia y de legitimación para interponer controversias constitucionales". Fusticia Electoral. Revista del Tribunal Electoral del Poder Fudicial de la Federación, vol. 1 (6).

Vergottini, Giuseppe de. 2000. Diritto costituzionale. Padova. Cedam.

Voermans, Wim y Albers, Pim. 2003. Council for the Judiciary in EU Countries. La Haya. European Comission for the Efficiency of Justice.

ZAGReBelsky, Gustavo. 1977. La giustizia costituzionale. Bologna. Il Mulino.

ZAGREBELSKY, Vladimiro. 2019. "Nozione e portata dell'indipendenza dell'Ordine giudiziario e dei giudici Ruolo del Consiglio superiore della magistratura". Osservatorio Costituzionale (6). 